\title{
Development of Lignin-Based Mesoporous Carbons for the Adsorption of Humic Acid
}

\author{
Monika A. Jedrzejczyk, Julian Engelhardt, Marko R. Djokic, Vitaliy Bliznuk, Kevin M. Van Geem, \\ An Verberckmoes, Jeriffa De Clercq, * and Katrien V. Bernaerts*
}

Cite This: ACS Omega 2021, 6, 15222-15235

Read Online

\section{ACCESS | Lill Metrics \& More | 回 Article Recommendations ｜（） Supporting Information}

ABSTRACT: There is an increasing urge to make the transition toward biobased materials. Lignin, originating from lignocellulosic biomass, can be potentially valorized as humic acid (HA) adsorbents via lignin-based mesoporous carbon (MC). In this work, these materials were synthesized for the first time starting from modified lignin as the carbon precursor, using the softtemplate methodology. The use of a novel synthetic approach, Claisen rearrangement of propargylated lignin, and a variety of surfactant templates (Pluronic, Kraton, and Solsperse) have been demonstrated to tune the properties of the resulting MCs. The obtained materials showed tunable properties (BET surface area: $95-367 \mathrm{~m}^{2} / \mathrm{g}$, pore size: $3.3-36.6 \mathrm{~nm}, V_{\mathrm{BJH}}$ pore volume: $0.05-$ $0.33 \mathrm{~m}^{3} / \mathrm{g}$, and carbon and oxygen content: 55.5-91.1 and 3.0$12.2 \%$, respectively) and good performance in terms of one of the highest HA adsorption capacities reported for carbon adsorbents (up to $175 \mathrm{mg} / \mathrm{g}$ ).

\section{INTRODUCTION}

The transition from a petroleum-based economy toward a biobased economy gained a lot of interest in recent years, both from industry and the academic world, due to environmental and sustainability concerns. Lignocellulosic biomass is an especially interesting feedstock because it is not competing with food and feed production. ${ }^{1}$ Depending on the biomass source, plant cell wall material is composed of cellulose (35$80 \%)$, hemicellulose (5-35\%), and lignin (15-35\%). ${ }^{2}$ There are multiple possibilities for their conversion from both cellulose and hemicellulose to ethanol, furfural, platform sugars, and their derivatives ${ }^{3-5}$ and from lignin to fuels, chemicals, and materials. ${ }^{4,6-8}$

Lignin is an amorphous material consisting of highly branched aromatic macromolecules based on three basic phenylpropanoid components (coumaryl, coniferyl, and sinapyl alcohols) bonded together. ${ }^{9}$ In nature, lignin provides lignocellulosic materials with inner strength, rigidity, and dimensional stability due to the chemical bonding with cellulose and hemicellulose, water impermeability and its transport within the plant, and it also has antioxidant, antimicrobial, and antifungal properties among others. ${ }^{10,11}$ Currently, lignin is considered as a byproduct of the lignocellulose bioethanol production and paper industry, and it has a relatively low value and quality. From the approx. 70100 million tons of lignin produced annually, only less than 5\% is not used as an energy source. ${ }^{12}$ To valorize lignin and

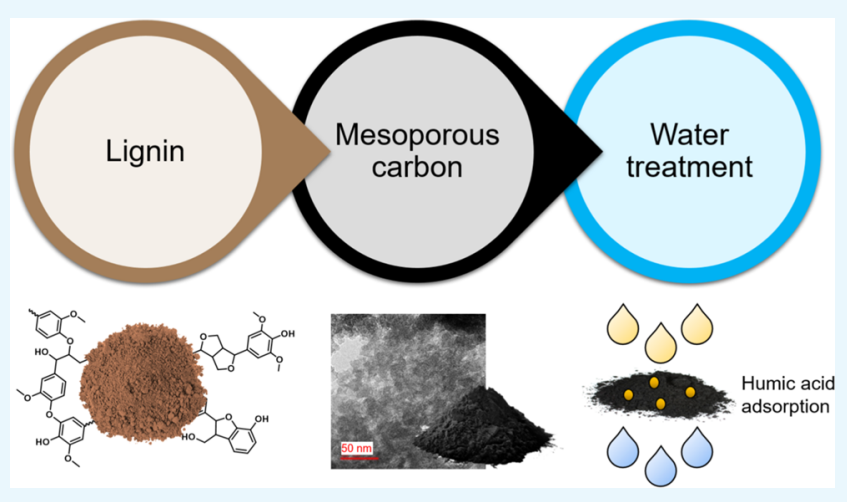

improve its use, high-value applications are being developed, and lignin biorefineries converting lignin into high-value products are increasingly drawing attention. ${ }^{13}$ Possible valueadded applications of lignin include its conversion to chemicals, fuels, and carbonous materials, its applications in polymeric materials for adhesives, coatings, and composites, and as antioxidant or flame retardant among others. ${ }^{7,8,11-15}$

Carbonous materials, such as mesoporous carbons (MCs), are widely used in multiple fields, such as adsorption, separation, catalysis, drug delivery, fuel cells, and energy storage and in electronics as a result of their excellent properties: unique morphology, high specific area, pore volume, and excellent mechanical, chemical, and thermal stability. ${ }^{16-21}$ They can be obtained via different routes: softand hard-templating, physical and chemical activation, sol-gel method, hydrothermal carbonization, or direct carbonization. ${ }^{16,19,20,22-24}$ In this research, the soft-templating method of a lignin precursor was applied. In this method, a carbon precursor is cross-linked in the presence of a structuredirecting agent (surfactant, block copolymer) after their self-

Received: March 18, 2021

Accepted: May 25, 2021

Published: June 4, 2021 

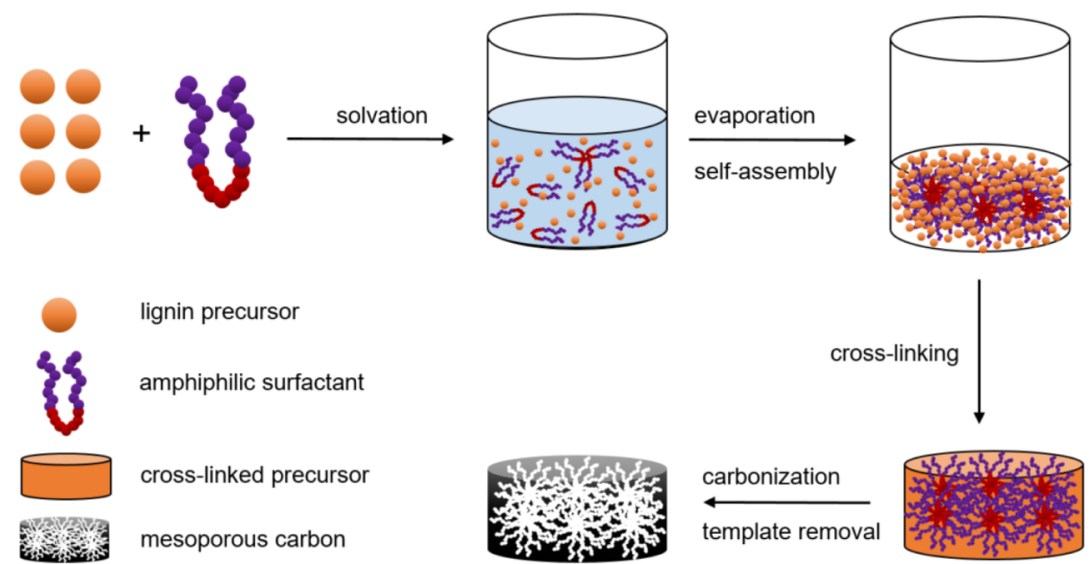

Figure 1. MC synthesis via the soft-templating EISA method. Adapted with permission from ref 28. Copyright 2014 Elsevier.

Lignin propargylation:

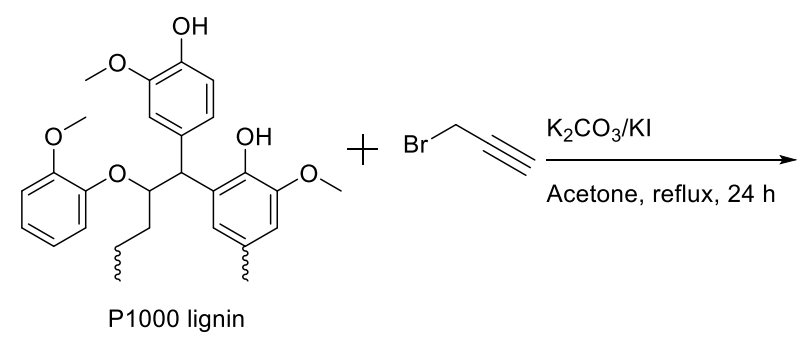

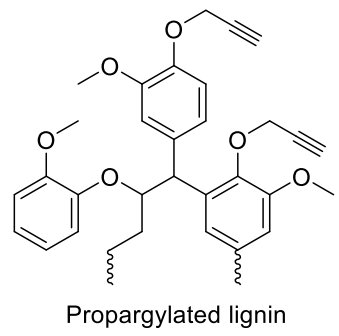

Lignin based resins preparation and curing via Claisen rearrangement:<smiles>[R]c1cc(OC)c(OC)cc1C(CCCC)c1cc(C)cc(OC)c1OC</smiles>

Propargylated lignin
1. surfactant, 2-Me-THF

2. EISA

3. $180^{\circ} \mathrm{C}, 14 \mathrm{~h}$<smiles>[R]c1c(OC)cc(C)cc1C(CCC)C(Oc1ccccc1OC)c1cc2c(c(OC)c1)OCC=C2</smiles>

Benzopyran

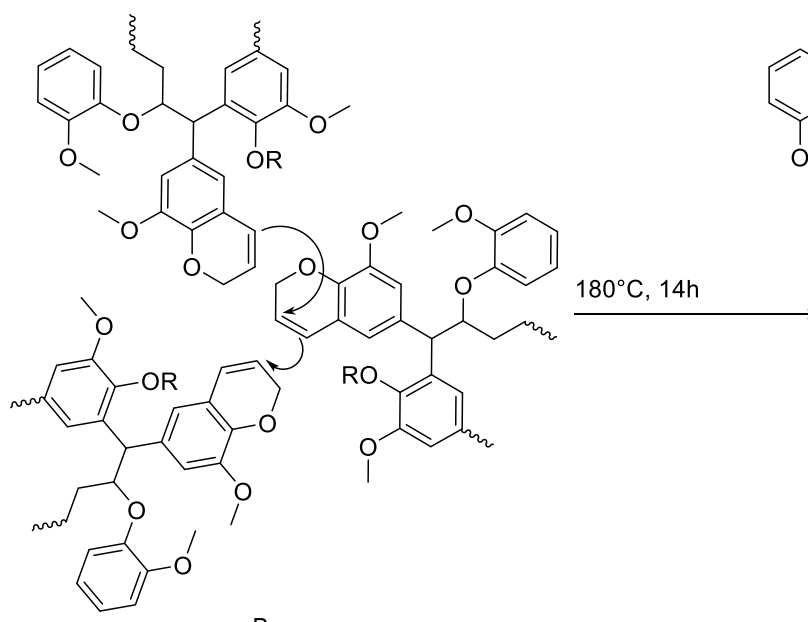

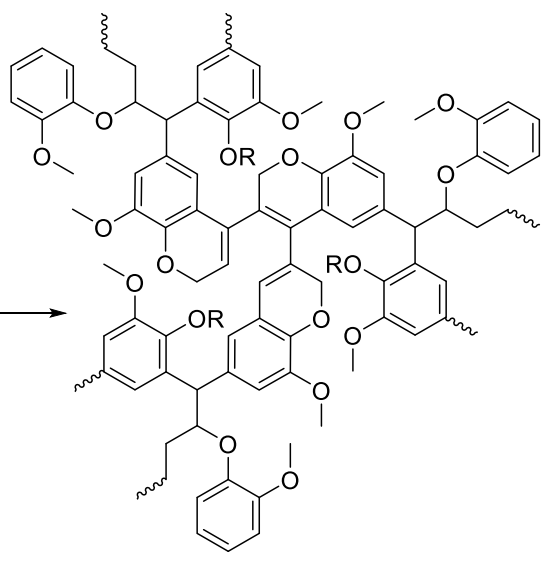

Benzopyran

Figure 2. Synthetic route of obtaining the lignin-based MC precursors via the soft-templating method. The resin is cured via Claisen rearrangement after lignin propargylation. 
assembly, to form an organized mesophase. Afterward, the surfactant is removed by means of a thermal treatment, followed by the carbonization of the cross-linked resins, as presented in Figure 1. One of the most common synthetic routes in soft-templating methods is evaporation-induced selfassembly (EISA). The principle of the EISA method is as follows: polymerizable precursors and structure-directing agents form micelles in the solution, and upon solvent evaporation, their concentration is increasing, promoting more organic-organic self-assembly of the components. ${ }^{25}$ Effective self-assembly is driven by the concentration gradient in EISA. ${ }^{26}$ Tunability of the MC properties is related to the selection of the precursor, synthetic route, surfactant type and concentration, and carbonization temperature. ${ }^{20,27}$

Commonly used petroleum-based carbon precursors for MCs are phenolic resins, such as phenol, resorcinol, or phloroglucinol-formaldehyde resins, phenolic-functionalized melamine, and (phenol)-urea-formaldehyde resins. $^{16,20,25,29-32}$ The synthesis of MCs from biobased precursors is gaining interest in modern materials science research, and it was described in multiple reviews. Precursors, such as plant biomass, lignin, fungus, algae, chitin, chitosan, gelatin, ionic liquids, various sugars, amino acids, and their derivatives, have been demonstrated. ${ }^{16,19,20,24,33-37}$ Use of lignin in this application has an advantage of using a non-toxic, renewable, and widely available resource, which is structurally similar to phenol-formaldehyde, one of the well-established precursors. Lignin can be incorporated into MC fabrication using various pathways, such as templating methods and physical and chemical activation. $15,38,39$

Lignin-based MCs fabricated via the soft-templating have been reported in the literature. ${ }^{40-45}$ In these reports, ligninformaldehyde or lignin-phenol/phloroglucinol-formaldehyde resins are synthesized and cured in the presence of a surfactant (Pluronic type), with the disadvantage of the use of toxic phenol and/or formaldehyde. In the next step, carbonization of the resin is performed. Such MCs have a relatively high surface area $\left(81-685 \mathrm{~m}^{2} / \mathrm{g}\right)$ and pore volume $\left(0.075-0.62 \mathrm{~cm}^{3} /\right.$ g). ${ }^{40-45}$ In general, lignin-based MCs find their applications in the fields of supercapacitors, conductive and energy storage materials, ${ }^{40,41,46-48}$ catalysis, $^{44}$ delivery systems, ${ }^{28,43}$ adsorption of organic molecules or heavy metals from water, ${ }^{49,50}$ or air pollutant adsorption. ${ }^{50,51}$

In contrast to the state-of-the-art, ${ }^{41-44,50,52}$ where the toxic formaldehyde is used to cross-link the system, we developed a formaldehyde-free method to cross-link lignin and for further MC fabrication. Here, propargyl-modified lignin was crosslinked via the Claisen rearrangement, in the presence of a surfactant, using the soft-templating EISA strategy (Figure 2). Propargylated lignin has been reported to self-cross-link via the Claisen rearrangement, ${ }^{53,54}$ and it can be used as a precursor in single component carbon fiber preparation. ${ }^{55}$ This is the first report of the Claisen-rearrangement approach for lignin crosslinking used for MCs precursor synthesis. Four different surfactants were selected as a template: Pluronic F127 and P123, Kraton G1652, and Solsperse M387. The most widely used surfactants are represented by the Pluronic family, consisting of poly(ethylene oxide) (PEO) and poly(propylene oxide) (PPO) block copolymers. The Pluronics were selected because they are up to now the workhorses for the preparation of MCs. While PPO orients toward the core of the micelles, PEO stretches out into the aqueous medium where it undergoes $\mathrm{H}$-bonding with, for example, $\mathrm{OH}$ groups in the carbonous precursor resin. In this work, we investigated surfactants with various levels of hydrophobicity. Therefore, more hydrophobic surfactants like Kraton G1652 and Solsperse M387 were tested. Those surfactants have not yet been reported as a template for MCs synthesis. Kraton G1652 is a hydrogenated triblock copolymer with polystyrene end blocks and a poly(ethylene/butadiene) middle block (SEBS), while Solsperse M387 is a basic and weakly cationic and Hbonding dispersant with known affinity for aromatics. ${ }^{56}$ They were selected based on their foreseen possibility to interact with the lignin precursor via $\pi-\pi$ stacking. Cured resins were carbonized at three different temperatures $(600,800$, and 1000 ${ }^{\circ} \mathrm{C}$ ), characterized, and applied as adsorbents for humic acid (HA).

$\mathrm{HA}$ is one of the components of the surface and ground water. It is a complex, polydisperse biomacromolecule, categorized as dissolved organic carbon. ${ }^{57} \mathrm{HA}$ dissolved in water not only influences the color, taste, and odor of water but also causes fouling during water purification, and it is a potential hazard for human health during potable water processing. ${ }^{58}$ It is a precursor to potentially carcinogenic trihalomethanes and haloacetic acids produced as byproducts during water disinfection by chlorine or chloramines. ${ }^{58,59}$ Moreover, HA tends to form organometallic complexes with heavy metals, increasing their bioavailability. ${ }^{60}$ There are multiple ways to remove HA from water, including adsorption, membrane filtration, coagulation, flocculation, electrochemical methods, catalytic oxidation, and decomposition. ${ }^{57,61}$ Adsorption is an important HA elimination technique. Examples, advantages, and disadvantages of the various adsorbents are a topic of multiple reviews. ${ }^{57,62,63}$ Those adsorbents can be categorized in the following groups: carbonaceous, mineral, and polymeric materials and (nano)composites and nanomaterials (nanoparticles and nanotubes). The examples of such materials are mesoporous and activated carbons, clays and zeolites, ion-exchange membranes, carbon nanotubes, and metallic nanoparticles and their composites, respectively. ${ }^{57,62,63}$ The MCs synthesized in this article will be benchmarked with state-of-art MC, synthesized using the lignin-formaldehyde approach (soft templated with Pluronic F127), ${ }^{42}$ and commercial activated carbon, to evaluate their performance as $\mathrm{HA}$ adsorbents.

The main objective of this work is the development of lignin-derived MCs suitable for the adsorption of HA. The strategy is to synthesize carbonous materials from lignin by its cross-linking via the Claisen rearrangement, in the presence of different surfactants, using the soft-templating EISA approach. The investigated surfactants varied in structure and hydrophobicity. The ultimate goal is to correlate the MC properties with their HA adsorbent capacity.

\section{RESULTS AND DISCUSSION}

2.1. MC Precursor Synthesis. The propargylated lignin is expected to interact with the outer part of the micelles, which is formed by the self-assembly of the surfactant as the solvent (2-methyltetrahydrofuran) evaporates. Upon heating above $150{ }^{\circ} \mathrm{C}$, Claisen rearrangement of the propargylated lignin takes place. ${ }^{53}$ First, benzopyran structures are formed through $[3,3]$ and $[1,5]$-sigmatropic and oxa-Diels-Alder reactions. ${ }^{64}$ Then, benzopyran moieties present in the modified lignin structure were thermally polymerized at $180{ }^{\circ} \mathrm{C}$ for $14 \mathrm{~h}$ to ensure maximal conversion (Figure 2). The conversion has been determined by means of FT-IR, by observing the 
disappearance of the alkyne moiety band $\left(3300 \mathrm{~cm}^{-1}\right)$. The conversion was high, in the range of $88-99 \%$, as shown in Figure 3. Examples of the spectra before and after cross-linking are shown in Figure S2, Supporting Information.

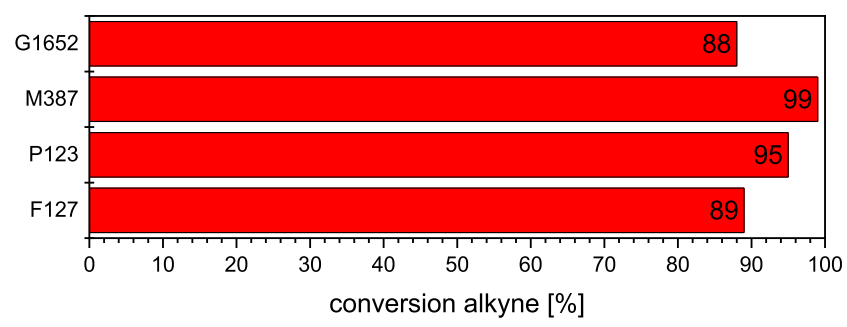

Figure 3. Claisen rearrangement conversion determined by FT-IR of P1000 lignin in the presence of the four surfactants.

2.2. MC Synthesis and Characterization. Once the lignin-based resins were cross-linked, they were carbonized at three different temperatures $\left(600,800\right.$, and $\left.1000^{\circ} \mathrm{C}\right)$. As lignin is carbonized, various pyrolyzates are formed at high temperatures: lignin dehydration and decarboxylation takes place, followed by the formation of polycyclic aromatic hydrocarbons (PAHs), coke, tar, and char. Above $400{ }^{\circ} \mathrm{C}$, methoxy groups in lignin are transformed to catecholic and pyrogallolic structures, together with side-chain $\mathrm{C}-\mathrm{C}$ and $\mathrm{C}-$ $\mathrm{O}$ bond cleavage, resulting in the start of lignin depolymerization and repolymerization and initial PAHs, char, and coke formation. ${ }^{65}$ Around $550{ }^{\circ} \mathrm{C}$, catecholic and pyrogallolic structures tend to be transformed into coke, together with increased $\mathrm{PAH}$ formation, especially when the temperature increases above $700{ }^{\circ} \mathrm{C}$. At elevated temperatures, largermolecular-weight PAHs are being formed. At temperatures above $1000{ }^{\circ} \mathrm{C}$, PAHs are the dominant product of lignin tar decomposition. ${ }^{66}$

It was generally observed that the carbon content, as determined by elemental analysis, increased with increasing carbonization temperature (Table 1). For instance, the MC P123, carbonized at $600{ }^{\circ} \mathrm{C}$, had 67.1 wt \% carbon, while the same resin carbonized at 800 and $1000{ }^{\circ} \mathrm{C}$ had a carbon content of 69.0 and $91.1 \mathrm{wt} \%$, respectively. G1652 and F127 resin sets were an exception, with a similar carbon content for 600 and $800{ }^{\circ} \mathrm{C}$ carbonized materials.

During lignin carbonization, oxygen containing moieties, such as hydroxyl, methoxy, and carbonyl groups, are removed, and the remaining carbon network is transformed to PAH, while the carbon framework remains. This explains the increased carbon content with carbonization temperature. ${ }^{67}$ This effect was observed for all the surfactants used in this study. MCs carbonized at $1000{ }^{\circ} \mathrm{C}$ exhibited a similar carbon content as the reference activated carbon, except for MC F127_1000.

Characterization of the synthesized MCs by elemental analysis did not yield a complete mass balance of $\mathrm{H}, \mathrm{O}, \mathrm{N}, \mathrm{S}$, and $\mathrm{C}$ atoms in most cases. Therefore, additional X-ray photoelectron spectroscopy (XPS) experiments were performed on P1000 lignin and propargylated P1000 lignin, and the P123 MC was set to investigate this issue. Elemental analysis provides information about the content of carbon, hydrogen, nitrogen, sulfur, and oxygen, while XPS can detect all elements except hydrogen and helium. XPS showed that sodium and chlorine are present in the MC samples (but not in P1000 lignin), up to 4.6 and 4.4 wt \%, respectively. Since the workup includes use of concentrated sodium chloride solution, those findings are plausible.

Nitrogen sorption measurements (Figure 4 for the materials carbonized at $800{ }^{\circ} \mathrm{C}$ and Figures S4 and S5, Supporting Information, for the materials carbonized at 600 and $1000{ }^{\circ} \mathrm{C}$ ) exhibited isotherms of type IVa for all the synthesized MCs, or isotherm type $\mathrm{Ib}$ for the commercial activated carbon, as expected. Materials with isotherm type IV are classified as mesoporous, while those which exhibit isotherm type I are considered to be microporous to mesoporous (with small mesopores, up to $2.5 \mathrm{~nm}$ ). ${ }^{68}$ It can be noticed that for F127 and P123 materials, the hysteresis is not closing. This phenomenon has been reported for calcinated phenolformaldehyde resins made with F127 template and may be related to swelling of the polymer in nonsolvent (here: condensed nitrogen). ${ }^{69,70}$ The carbonized materials exhibited different hysteresis loops, associated with capillary condensation, pores blocking, and/or cavitation-controlled evaporation. A H2a hysteresis loop was observed for F127 carbonized materials, which is typical for the materials exhibiting pores

Table 1. Characteristics of the MCs and Activated Carbon

\begin{tabular}{|c|c|c|c|c|c|c|c|c|}
\hline material & $S_{\mathrm{BET}}{ }^{a}\left[\mathrm{~m}^{2} / \mathrm{g}\right]$ & $V_{\mathrm{BJH}}^{b}\left[\mathrm{~cm}^{3} / \mathrm{g}\right]$ & $V_{\text {micro }}{ }^{c}\left[\mathrm{~cm}^{3} / \mathrm{g}\right]$ & $D_{\mathrm{p}} \mathrm{BJH}^{d}[\mathrm{~nm}]$ & $\mathrm{C}^{e}[\mathrm{wt} \%]$ & $\mathrm{H}^{e}[\mathrm{wt} \%]$ & $\mathrm{N}^{e}[\mathrm{wt} \%]$ & $\mathrm{O}^{e}[\mathrm{wt} \%]$ \\
\hline activated carbon & 1126 & 0.32 & 0.22 & 2.7 & 86.0 & 0.3 & 4.5 & 9.1 \\
\hline G1652_600 & 136 & 0.05 & 0.04 & 34.4 & $58.5 \pm 0.6$ & $1.6 \pm 0.1$ & $<1$ & $3.0 \pm 0.1$ \\
\hline G1652_800 & 102 & 0.08 & 0.03 & 22.5 & $55.5 \pm 2.1$ & $<1$ & 1.4 & $12.2 \pm$ N.A. \\
\hline G1652_1000 & 107 & 0.07 & 0.03 & 36.6 & $91.0 \pm 1.2$ & $<1$ & 1.6 & $8.2 \pm 0.3$ \\
\hline M387_600 & 242 & 0.14 & 0.06 & 5.8 & $58.9 \pm 0.8$ & $1.7 \pm 0.1$ & $3.8 \pm 0.1$ & $6.1 \pm 0.5$ \\
\hline M387_800 & 95 & 0.12 & 0.02 & 5.4 & $63.9 \pm 2.2$ & $<1$ & $4.6 \pm 0.3$ & $9.6 \pm 0.4$ \\
\hline M387_1000 & 142 & 0.15 & 0.03 & 5.4 & $84.7 \pm 0.8$ & $1.2 \pm 0.1$ & $3.0 \pm 0.1$ & $11.4 \pm 0.2$ \\
\hline P123_600 & 371 & 0.30 & 0.10 & 10.2 & $67.1 \pm 0.3$ & $1.7 \pm 0.1$ & $<1$ & $5.8 \pm 0.2$ \\
\hline P123_800 & 277 & 0.28 & 0.07 & 12.2 & $69.0 \pm 0.3$ & $1.1 \pm 0.1$ & $<1$ & $8.5 \pm 0.1$ \\
\hline P123_1000 & 291 & 0.33 & 0.06 & 10.7 & $91.1 \pm 1.7$ & $1.1 \pm 0.1$ & $<1$ & $9.0 \pm 0.1$ \\
\hline F127_600 & 367 & 0.14 & 0.09 & 3.7 & $63.9 \pm 0.5$ & $1.7 \pm 0.1$ & $<1$ & $5.5 \pm 0.2$ \\
\hline F127_800 & 348 & 0.12 & 0.09 & 3.3 & $72.2 \pm 0.4$ & $<1$ & $<1$ & $3.6 \pm 0.2$ \\
\hline F127_1000 & 217 & 0.12 & 0.04 & 3.5 & $77.4 \pm 1.1$ & $<1$ & $<1$ & $7.4 \pm 0.1$ \\
\hline
\end{tabular}

${ }^{a}$ Determined using the Brunauer-Emmett-Teller (BET) method. ${ }^{b} \mathrm{BJH}$ desorption cumulative volume of pores between 17.000 and 3,000.000 $\AA$ width. No pore volume was detected above $50 \mathrm{~nm}$ in pore size distribution. ${ }^{c}$ Calculated by the $\mathrm{BJH}$ model from the desorption branches of the isotherm. ${ }^{d}$ Calculated by the $V-t$ method. ${ }^{e}$ Determined by elemental analysis. 

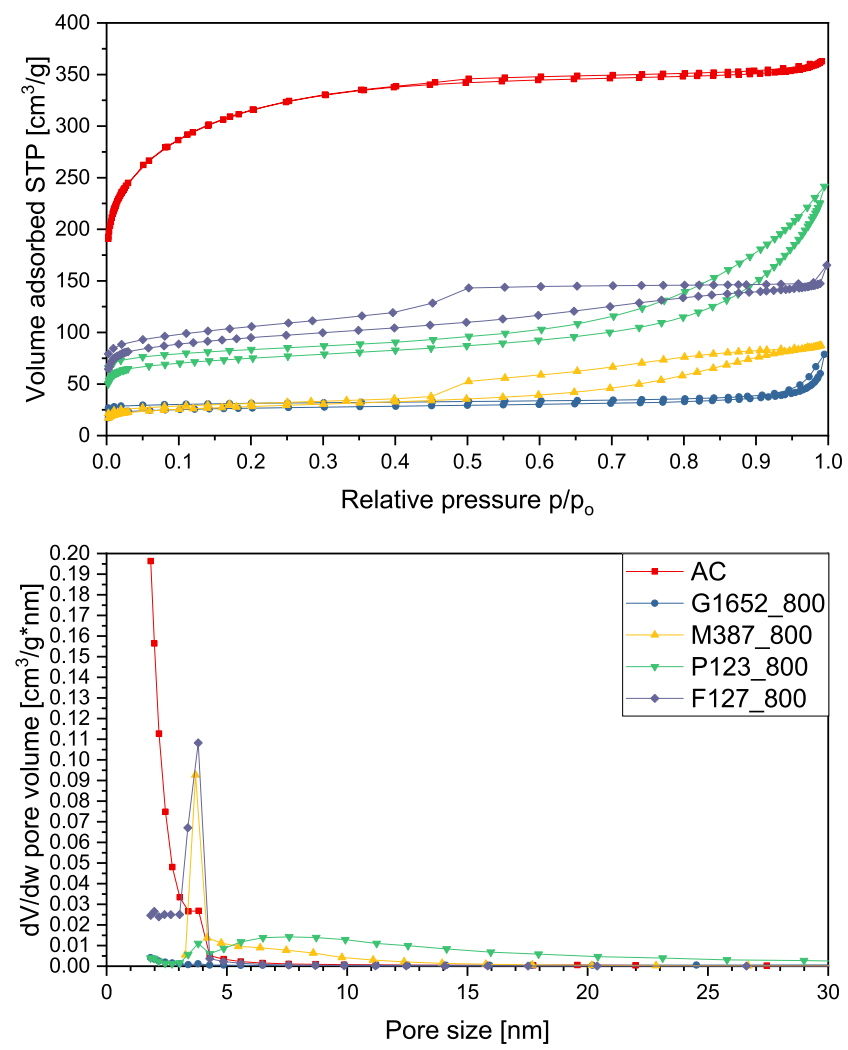

Figure 4. Nitrogen sorption isotherm (top) and PSD (bottom) of the resins carbonized at $800{ }^{\circ} \mathrm{C}$.

blocking in a narrow range of pore necks or cavitation-induced evaporation. ${ }^{68} \mathrm{M} 387$ carbonized materials showed a combination of $\mathrm{H} 2 \mathrm{a}$ and $\mathrm{H} 2 \mathrm{~b}$ hysteresis loops, which indicates pores blocking caused by both narrow and wide pore necks, what can be supported by the pore size distribution (PSD). ${ }^{68}$ Another type of hysteresis loop, which was found for G1652 and P123 carbonized materials, was type $\mathrm{H} 4$, often seen for micro-MC systems. ${ }^{68}$ Together with a shift of the hysteresis position to higher $p / p_{0}$ values, an increase in the pore size was observed (Figure 4).

The results, as listed in Table 1 , clearly indicate the importance of the selection of the right surfactant in order to tune the pore size and volume. Exceptionally good results in terms of Barrett-Joyner-Halenda (BJH) pore volume were obtained for P123, followed by F127. Possibly, the interaction of those two surfactants, characterized by the different length of the PPO-PEO-PPO units (Pluronic F127 $\mathrm{PEO}_{106}-$ $\mathrm{PPO}_{70}-\mathrm{PEO}_{106}$ and Pluronic P123 $\mathrm{PEO}_{20}-\mathrm{PPO}_{70}-\mathrm{PEO}_{20}$ ), results in different micellization efficiency due to the ratio of PEO to PPO units. Overall, the Pluronic surfactants in Claisen rearrangement-based lignin cross-linking tend to be a better precursor to mesoporous materials as the MCs templated by them exhibited higher BET surface areas and higher pore volumes (Figure 5).

The difference in material properties may arise due to different properties of the surfactant, such as chemical structure, chain architecture, chain lengths and ratio, and so forth, which result in different types of interactions (selfassembly of the structure-directing agent and the precursor) influencing the structure of the resulting MCs. ${ }^{71}$ For instance, there is hydrogen bonding between the hydroxyl functional groups of lignin (phenolic $\mathrm{OH}$ and aliphatic $\mathrm{OH}$ groups) and
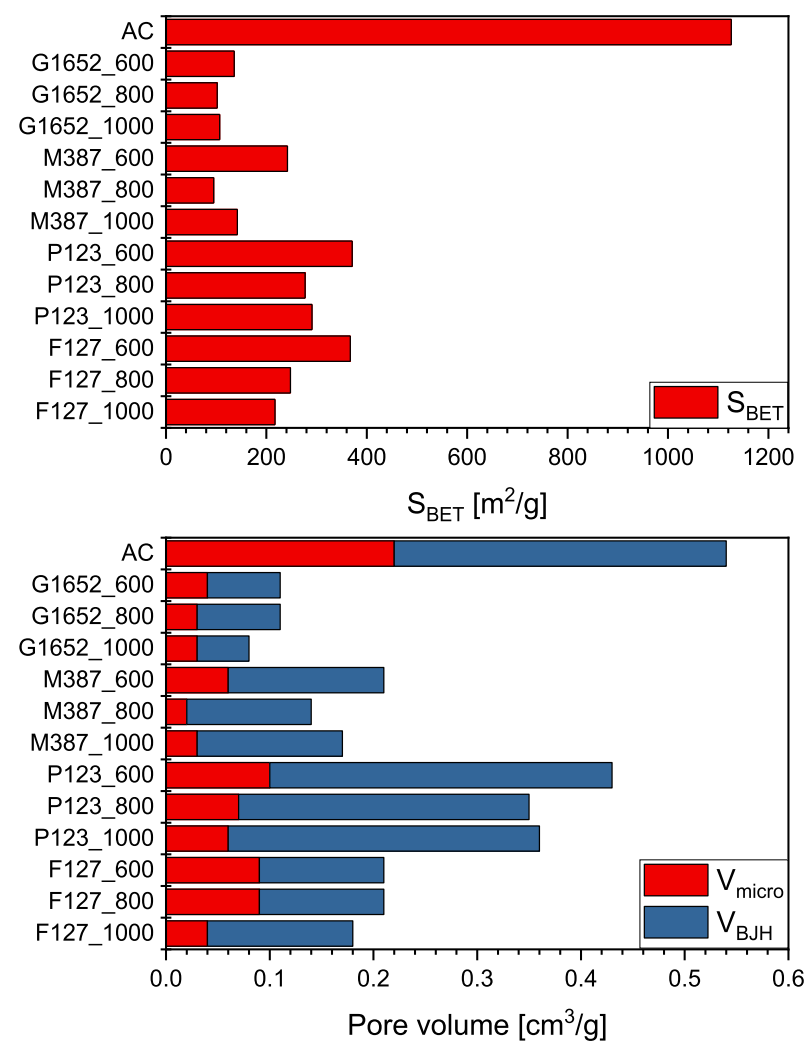

Figure 5. Summary of total BET surface areas (top) and pore volumes (bottom) of the synthesized MCs.

the ethers of the hydrophilic PEO outer blocks of the micelles, with the hydrophobic PPO buried inside to avoid contact with the hydrophilic hydroxyl groups in lignin Pluronics. ${ }^{27,72}$ Kraton G1652 [a poly(styrene-ethylene/butadiene-styrene) (SEBS) elastomer] and Solsperse M387 (a basic and weakly cationic and H-bonding dispersant) may interact via weaker hydrophobic interactions and/or $\pi-\pi$ stacking with aromatic moieties in the modified lignin. The stronger interactions between lignin and Pluronics can explain the better material properties obtained with those surfactants compared to the hydrophobic surfactants. Especially, interesting MCs were obtained with a Pluronic P123 template. Those MCs had the highest surface area $S_{\mathrm{BET}}$, combined with the highest $V_{\mathrm{BJH}}$ pore volume. Another interesting case was the MCs templated with Pluronic F127. Those materials showed similar surface area and slightly lower $V_{\mathrm{BJH}}$ pore volume. Interestingly, materials templated with Pluronic F127 exhibited narrow PSD, with a major peak at $4 \mathrm{~nm}$, while Pluronic P123 had a wide peak with a maximum at $8 \mathrm{~nm}$, tailing to $80 \mathrm{~nm}$. The broader PSD with Pluronic P123 as template can be correlated to the shorter hydrophilic PEO segment $\left(\mathrm{PEO}_{20}\right)$ compared to that of F127 $\left(\mathrm{PEO}_{106}\right)$, resulting in weaker hydrogen bonding between the template and precursor. ${ }^{73}$ Materials prepared with those two surfactants showed a decrease in surface area with increasing carbonization temperature, which can be a result of the pore shrinking and/or collapse during the carbonization process. This may also cause a lower pore volume.

The obtained TEM images (Figure 6) confirm the observations from nitrogen sorption data regarding the morphology of the pores. Activated carbon consists of a bulky structure, with micro- and mesopores. In the TEM micrographs of M387_800, the porous domains are visible. 


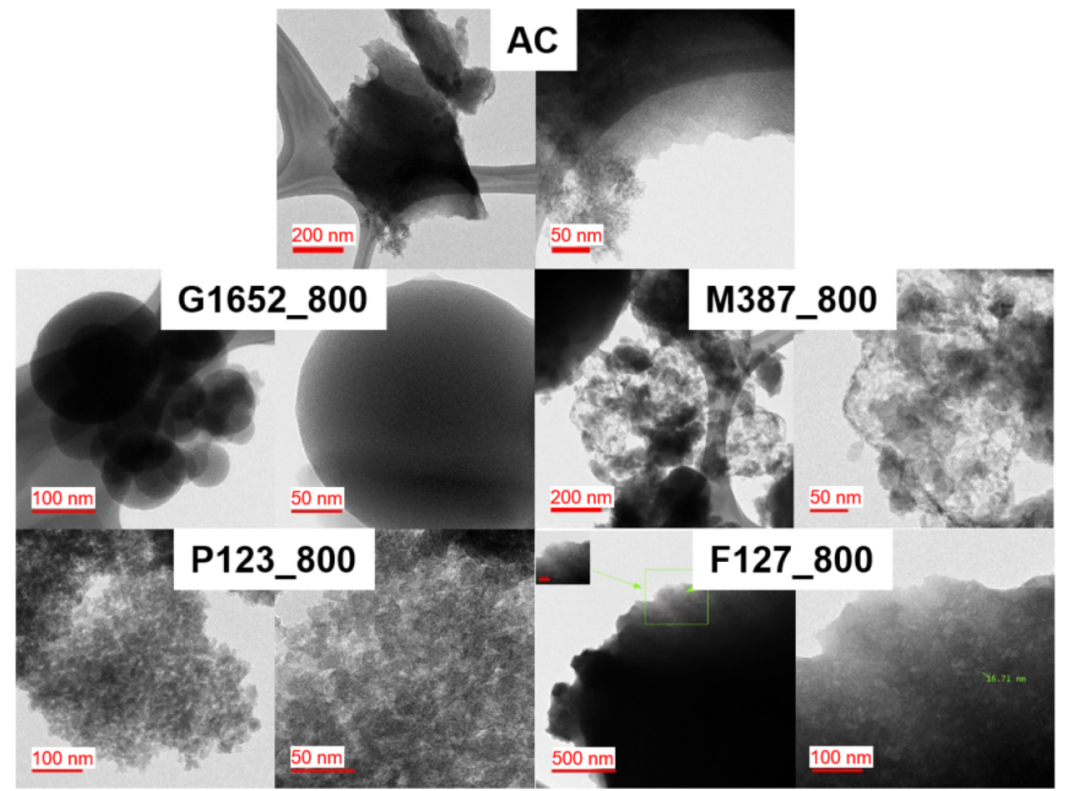

Figure 6. TEM micrographs of activated carbon and lignin-based resins carbonized at $800{ }^{\circ} \mathrm{C}$.

Mostly small, uniform mesopores are observed, which is supported by the nitrogen sorption data. P123_800 consists of a more confined structure, with clearly visible mesopores and possibly macropores. A high number of pores are visible, which was also observed in the nitrogen sorption data, represented by the high pore volume. In F127_800, mesoporous domains can be observed, randomly distributed. The number of pores seems to be moderate, but the pores tend to have a relatively narrow size range.

Surprisingly, Kraton G1652 templated MCs exhibited spherical carbon domains along the agglomerated structures. These spherical structures range from $20 \mathrm{~nm}$ to $1 \mu \mathrm{m}$ in diameter. These spheres are observed only in the G1652 templated carbons. Due to the dense structure of the spheres, visualization of distinct pores is hindered, which could also be explained by the low pore volume observed in nitrogen sorption experiments. The carbon (nano)spheres morphology could originate from the interaction with the surfactant, which may enable lignin to rearrange in these spherical structures during the EISA step. Kraton G1652 consists of SEBS units and is consequently hydrophobic. During the resin synthesis, the surfactant is interacting with the hydrophobic and aromatic domains of the lignin precursor. The hydrophilic domains, for example, remaining hydroxyl groups in lignin, could have been repelled by the surfactant and agglomerated together via hydrogen bonding. This self-assembly could have resulted in the spherical structures, which are observed for the carbonized materials. $\mathrm{Li}$ et al. reported the synthesis of MC spheres, with $1320 \mathrm{~m}^{2} / \mathrm{g}$ specific surface area and $3.5 \mathrm{~cm}^{3} / \mathrm{g}$ pore volume with a hierarchical pore size of $3.5-60 \mathrm{~nm}$ via a dual templating method, soft and hard templating. ${ }^{74}$ The carbon spheres exhibited a more defined pore structure compared to the material obtained by Kraton G1652, and the spheres they obtained were in the range of 3-5 $\mu \mathrm{m} .{ }^{74}$ The synthesized novel material could open an alternative way to synthesize porous carbon nanospheres.

The synthesized carbons can be benchmarked with literature results where a soft-templating approach with lignin as a precursor and Pluronic F127 as a template was used (Table 2). The resin cross-linking uses very harmful formaldehyde or less harmful glyoxal, while the lignin precursor is different in all the reported cases. Here, we propose lignin cross-linking via the Claisen rearrangement as an alternative. The surface area of the MCs obtained in our study is similar to the phenolformaldehyde references, except from the one reported by Chen et al. ${ }^{40}$ In that study, a high amount of $\mathrm{KOH}$ was used, which can increase the porosity by chemical activation in the MC synthesis combined with the soft-templating methodology. The total pore volume of our materials is comparable with that reported by Saha et al. ${ }^{43}$ and lower than that reported by Chen et $a l^{40}$ and Qin et $a l^{42}$ but better than the ones obtained by Herou et $a .^{41}$ When the pore volume of the mesopores is compared, the best-performing materials from this study are superior to all the references, except for that reported by Saha et al. $^{43}$ and Chen et al., ${ }^{40}$ showing similar or slightly better characteristics. Pore sizes of our MCs vary between 3.3 and $36.6 \mathrm{~nm}$. PSD is related to the surfactant used as a template. All the literature references using the lignin-formaldehyde cross-linking approach used Pluronic F127 as a template, and the pore size was in the range of 3.4-3.8 nm, which is in the same range as our materials templated with Pluronic F127 $(3.3-3.7 \mathrm{~nm})$. The use of another template enables to tune this property, as presented in Table 1 . In general, materials presented in this study exhibit good performance compared with what has been reported already in the field of porous lignin materials, with the advantage that our materials are prepared via a formaldehyde-free synthesis route.

Unfortunately, none of our synthesized MCs exhibited an ordered porous structure, which has been reported by Qin et al. ${ }^{42}$ and Wang et $a l^{45}$ The formation of ordered pores arises from the high hydroxyl group content of the used lowmolecular-weight lignin (1-1.5 kDa used by Qin et al., ${ }^{42}$ and $M_{\mathrm{w}}$ of lignin used by Wang et al. ${ }^{45}$ was not reported), which enables conductive self-assembly of the micelles. ${ }^{75}$ Therefore, the observed non-ordered pore structure in our case could arise from a lower amount of hydroxyl groups $(0.79 \mathrm{mmol} / \mathrm{g}$, unmodified P1000 $5.51 \mathrm{mmol} / \mathrm{g}$ ) after the functionalization of the lignin precursor with propargyl units and its relative higher molecular weight $(4.3 \mathrm{kDa})$ compared to the lignin used by Qin et al. ${ }^{42}$ By consequence, the H-bond interaction between 
our propargylated lignin precursors and the surfactant is weaker (there are less hydrogen bonds), resulting in less ordered porous materials because the interactions are already destroyed in the heating process.

2.3. HA Adsorption Studies. The main objective of this work was the development of the MCs suitable for the adsorption of HA and to correlate their properties with the adsorbent capacity. The synthesized MCs are compared with activated carbon by benchmarking their HA adsorption capacities. The results are summarized in Figure 7.

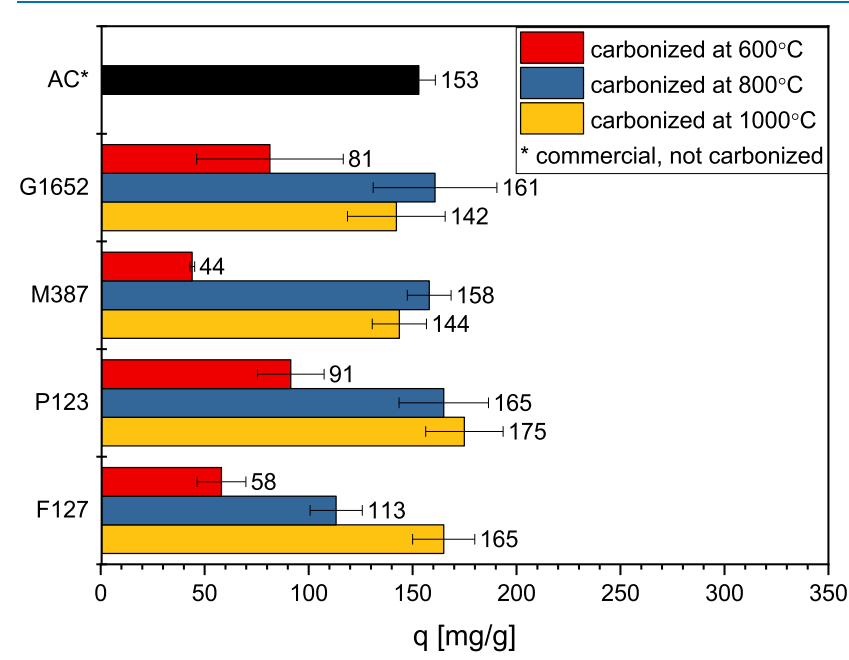

Figure 7. Comparison of HA adsorption of activated carbon and mesoporous materials synthesized in this study.

Activated carbon showed a HA adsorption capacity of 153 $\mathrm{mg} / \mathrm{g}$. Other reported commercial activated carbons exhibited lower HA adsorption capacities (up to $56 \mathrm{mg} / \mathrm{g}$ ) than the activated carbon used in this study, probably because of lower specific surface area, $\left(V_{\mathrm{BJH}}\right)$ pore volume, and pore size of those activated carbons. ${ }^{76-80}$ The HA adsorption on activated carbon is hindered by the size exclusion effect due to the small pore size. ${ }^{81}$ The adsorption capacity of activated carbon is in the same range as the G1652_800, G1652_1000 M387_800, M387_1000, P123_800, P123_1000, and F127_1000 MCs. $\mathrm{HA}$ adsorption for materials carbonized at 800 and $1000{ }^{\circ} \mathrm{C}$ is comparable for most of the materials, except for the F127 set, where adsorption of the material carbonized at $1000{ }^{\circ} \mathrm{C}$ is significantly increased compared to the $800{ }^{\circ} \mathrm{C}$ one. Materials carbonized at $600{ }^{\circ} \mathrm{C}$ showed the lowest HA adsorption in each set, with pronounced difference in the performance compared to materials carbonized at higher temperatures and reference activated carbon. This could be attributed to the fact that the materials carbonized at $600{ }^{\circ} \mathrm{C}$ showed the lowest carbon content (Table 1).

Libbrecht et al. reported that an increase in the pore size and carbon content promote higher HA adsorption due to the hydrophobic $\pi-\pi$ stacking adsorption mechanism. ${ }^{67}$ Unfortunately, we do not observe it for our materials, which have a lower carbon content than the ones reported by Libbrecht $e t$ al. which have $77-95 \%$ carbon. The lower carbon content in the reported materials would be expected to yield in lower adsorption since carbon enhances the hydrophobic character of the material and therefore the van der Waals and hydrophobic interactions. ${ }^{67}$ Upon a $\mathrm{pH}$ increase, the carboxyl groups of the HA deprotonate first $\left(\mathrm{pK} K_{\mathrm{a}}=5\right)$, and at higher $\mathrm{pH}$ 
Table 3. Comparison of Carbon Materials Used as HA Adsorbents

\begin{tabular}{|c|c|c|c|c|c|c|}
\hline material & $\begin{array}{l}S_{\mathrm{BET}}^{a} \\
{\left[\mathrm{~m}^{2} / \mathrm{g}\right]}\end{array}$ & $D_{p}$ BJH & $V_{\text {tot }}\left[\mathrm{cm}^{3} / \mathrm{g}\right]$ & $\begin{array}{l}\text { HA adsorption } \\
\quad[\mathrm{mg} / \mathrm{g}]\end{array}$ & $\begin{array}{l}\text { conditions } \\
\left(\mathrm{pH}, \text { temp }\left[{ }^{\circ} \mathrm{C}\right]\right)\end{array}$ & ref. \\
\hline commercial filtrasorb 200 activated carbon & NA & NA & NA & 24 & $5.0,25$ & 76 \\
\hline commercial adsorbent JZN & 149 & NA & $0.63^{\mathrm{b}}$ & 3 & $7.0,25$ & 83 \\
\hline commercial, treated coconut shell-based activated carbons & NA & NA & NA & $8-70$ & NA, 30 & 80 \\
\hline $\begin{array}{l}\text { commercial activated carbon treated with sulfuric and } \\
\text { phosphoric acids }\end{array}$ & $659-724$ & NA & NA & $19-26$ & NA, RT & 77 \\
\hline commercial cellulose and powdered activated carbon & $102-834$ & NA & NA & $89-30$ & $2.0,37$ & 79 \\
\hline chitosan-treated granular activated carbon (filtrasorb 400) & NA & NA & NA & $56-71$ & $7.0,25$ & 78 \\
\hline chitosan-encapsulated activated carbon & $316^{b}$ & $3.28^{b}$ & $0.26^{b}$ & 72 & $6.4,30$ & 85 \\
\hline ammonia and hydrogen-treated mesoporous activated carbons & $415-518$ & NA & $0.51-0.53^{c}$ & $90-137$ & NA, RT & 84 \\
\hline coal-based mesoporous activated carbons & $367-850$ & NA & $0.24-0.47^{b}$ & $170-200$ & $12.0-12.5,25$ & 82 \\
\hline soft-templated MCs based on resorcinol-formaldehyde resins & $422-670$ & $3.5-27^{d}$ & $0.74-1.56^{c}$ & $155-352$ & $7.0,25$ & 67 \\
\hline hard-templated (mesoporous $\mathrm{SiO}_{2}$ ) ordered $\mathrm{MC}$ & 988 & NA & $1.33^{c}$ & 51 & $6.0,25$ & 81 \\
\hline carbonized rice containing nanosized magnetite & NA & NA & NA & 80 & 7.61, RT & 87 \\
\hline $\begin{array}{l}\text { magnetic porous carbon based on pyrolyzed biomass } \\
\text {, containing } \gamma-\mathrm{Fe}_{2} \mathrm{O}_{3}\end{array}$ & 63 & NA & NA & 96 & $5.0, \mathrm{NA}$ & 88 \\
\hline $\begin{array}{l}\text { dual-pore carbon shells synthesized by templating against silica } \\
\text { nanospheres }\end{array}$ & $750-1350$ & $2.4-9.5^{b}$ & $0.4-1.1^{b}$ & $12-100$ & NA, 25 & 86 \\
\hline P123_1000 & 290 & $10.7^{d}$ & $0.37^{c}$ & 175 & $7.0,25$ & $\begin{array}{l}\text { this } \\
\text { work }\end{array}$ \\
\hline P123_800 & 277 & $12.2^{d}$ & $0.28^{c}$ & 165 & $7.0,25$ & $\begin{array}{l}\text { this } \\
\text { work }\end{array}$ \\
\hline F127_1000 & 156 & $3.5^{d}$ & $0.12^{c}$ & 165 & $7.0,25$ & $\begin{array}{l}\text { this } \\
\text { work }\end{array}$ \\
\hline G1652_800 & 102 & $22.5^{d}$ & $0.07^{c}$ & 161 & $7.0,25$ & $\begin{array}{l}\text { this } \\
\text { work }\end{array}$ \\
\hline M387_800 & 95 & $5.4^{d}$ & $0.13^{c}$ & 158 & $7.0,25$ & $\begin{array}{l}\text { this } \\
\text { work }\end{array}$ \\
\hline $\mathrm{AC}$ & 1026 & $2.3^{d}$ & $0.50^{c}$ & 153 & $7.0,25$ & $\begin{array}{l}\text { this } \\
\text { work }\end{array}$ \\
\hline
\end{tabular}

${ }^{a}$ Determined using the BET method. ${ }^{b}$ Not defined in the experimental section how this value was obtained. ${ }^{c}$ Calculated as the amount of nitrogen adsorbed at a relative pressure of $0.95 .{ }^{d}$ Calculated by the $\mathrm{BJH}$ model from the desorption branches of the isotherm.

values, the phenolic hydroxyl groups $\left(\mathrm{p} K_{\mathrm{a}}=10\right)$ deprotonate as well. This makes HA more hydrophilic. The adsorption experiments were performed at a $\mathrm{pH}$ of 7 ; therefore, the $\mathrm{HA}$ will be charged and become more hydrophilic. It was observed that the MCs, which had an oxygen content above 7 wt \%, showed good HA adsorption if they exhibited moderate to good material properties, such as surface area and mesoporous volume. A possible explanation might be the presence of noncovalent interactions between $\mathrm{HA}$ and the adsorbent, for example, hydrogen bonding. The hydrogen bonding could enhance the interaction strength between the adsorbent and the adsorbate and increase the adsorption capacity. Therefore, the increased oxygen content can be beneficial for HA adsorption. Additionally, the large pore size enables the adsorption of HA, whose reported hydrodynamic radius is $7.1 \mathrm{~nm} .{ }^{27}$ For materials with a pore size lower than $7.1 \mathrm{~nm}$, the size exclusion effect may prevent the adsorption of large amounts of HA.

Unfortunately, it is difficult to draw general conclusions regarding the relationship between synthesis route (used approach, surfactant, and experimental conditions), materials properties, and HA adsorption. For each case, the surfactant had a different effect on the properties of the materials, and therefore, the combination of different factors (BET surface area, pore volume, diameter, and elemental composition) influenced the adsorption properties. As multiple properties influence $\mathrm{HA}$ adsorption, it is very difficult to understand the interplay between them and the HA adsorption. The G1652 MCs exhibited good to very good HA adsorption, despite the low pore volume. Their performance can be connected with the high oxygen content in those MCs, combined with big pore sizes. M387 materials, on the other hand, exhibited low pore sizes, but their good performance can be attributed to the high oxygen content and moderate mesoporous volume. P123 MCs have the best performance from all the synthesized materials, and the excellent performance can be the result of the combination of the highest mesoporous volume, high BET surface area, pore size above $10 \mathrm{~nm}$, and high oxygen content. F127 materials exhibited moderate to good performance, which can be correlated with the high BET surface area and moderate mesoporous volume.

When compared with other carbon materials used for HA adsorption (Table 3), it turns out that the performance of the materials synthesized in this study is very good and is outperformed only by the materials synthesized from resorcinol-formaldehyde resin by Libbrecht et al. and coalbased mesoporous activated carbons prepared by LorencGrabowska et al. ${ }^{67,82}$ Other materials have significantly lower HA adsorption capacity than our materials, despite their usually higher surface areas and pore volumes. ${ }^{81,83-86}$ In comparison to commercial activated carbons, their performance is drastically lower than the MCs presented in this study. $^{76-80}$

\section{CONCLUSIONS}

A series of novel, lignin-based MCs were successfully prepared using a Claisen rearrangement route. The soft-templating method using EISA was applied to obtain mesoporous materials after carbonization. We presented the material characteristics obtained through the synthesis using various 
surfactants used as a template and at different carbonization temperatures. All the materials are benchmarked as HA adsorbents. The ultimate goal of this study was to correlate carbonous material properties with the humic adsorption capacity. High HA adsorption can be influenced by various properties of MCs, such as carbon and oxygen content, pore size, volume, and BET surface area. These properties can be steered by changing the surfactant type and concentration, resin preparation methodology, and carbonization temperature; however, it is not easy to understand the complex interplay between all these aspects in the material preparation.

The MCs synthesized in this research exhibited excellent performance as HA adsorbents compared to other carbonous materials in terms of adsorption capacity. The best results are obtained with Pluronic P123 surfactant and carbonized at 1000 ${ }^{\circ} \mathrm{C}$ because this material possesses high surface area and pore volume with average pore size above $7 \mathrm{~nm}$, with one of the highest carbon content obtained in this study. This work is one of the examples of lignin use in value-added applications, such as adsorbents for water purification, which is an interesting highlight adding to lignin valorization. This is a proof-ofprinciple application, but we believe that it is possible to use these materials for other applications as well, such as supercapacitors and energy storage materials. ${ }^{16,20,89,90}$

\section{EXPERIMENTAL SECTION}

4.1. Chemicals. All chemicals were used as received, unless stated otherwise. Protobind P1000 Lignin, soda lignin extracted from wheat straw $\left[M_{\mathrm{w}}=4.3 \mathrm{kDa}, \mathrm{D}=2.6\right.$, measured on a gel permeation chromatograph (GPC) with refractive index (RI) detection, calibrated with polystyrene standards, using tetrahydrofuran as the eluent, after acetylation of the lignin, ${ }^{91}$ was provided by Green Value S.A. It contains less than 4 wt \% carbohydrates and less than 2 wt \% ash. Elemental analysis of this lignin yields the following composition: 59\% C, $6 \% \mathrm{H}, 26 \% \mathrm{O}, 1 \% \mathrm{~N}$, and $0.1 \%$ S. ${ }^{92}$ Propargyl bromide solution ( $80 \mathrm{wt} \%$ in toluene solution, with $0.3 \%$ magnesium oxide as the stabilizer), potassium iodide ( $\geq 99.5 \%)$, potassium carbonate $(\geq 99.0 \%)$, Pluronic F127 [poly(ethylene oxide) ${ }_{106}$ poly $(\text { propylene oxide })_{70}-$ poly $(\text { ethylene oxide })_{106}, M_{\mathrm{w}}=$ $12,600 \mathrm{~g} \mathrm{~mol}^{-1}$ ], Pluronic P123 [poly(ethylene oxide) $)_{20}$ poly(propylene oxide $)_{70}$-poly(ethylene oxide $)_{20}, M_{\mathrm{w}}=5,800 \mathrm{~g}$ $\left.\mathrm{mol}^{-1}\right]$, formalin solution $\left(37 \%\right.$ in $\mathrm{H}_{2} \mathrm{O}$, with $10-15 \%$ methanol as the stabilizer), sodium hydroxide $(\geq 98 \%)$, nitric acid (70\%), 2-methyltetrahydrofuran (2-Me-THF) (anhydrous $>99.0 \%$ ), cyclohexanol (99\%), pyridine (dried over molecular sieves, 99.8\%), chromium(III) acetylacetonate (99.99\%), HA (>99\%), and hydrochloric acid (37\%) were purchased from Sigma-Aldrich. Acetone, ethyl acetate, and tetrahydrofuran were purchased from Biosolve. Molecular sieves (3 $\mathrm{A})$ were purchased from Merck. Chloroform-d (dried over molecular sieves, D, 99.96\%) was purchased from Cambridge Isotope Laboratories. The linear triblock copolymer based on SEBS with a styrene/rubber ratio of 30/70 Kraton G1652 (Kraton Cooperation) was kindly provided by Kraton Polymers Belgium. The Solsperse M387 dispersant (Lubrizol Corporation) was kindly provided by Integrated Chemicals Specialties BV. Activated carbon, Organosorb 200-1, was kindly provided by Desotec.

4.2. Synthesis. 4.2.1. Lignin Propargylation. The propargylation of P1000 lignin (Figure 2) was performed in a $4 \mathrm{~L}$ reactor, equipped with a reflux condenser and mechanical stirrer, under nitrogen flow. First, $200 \mathrm{~g}$ (1.29 mol, 1 equiv of the sum of phenolic, aliphatic $\mathrm{OH}$ and $\mathrm{COOH}$ groups) of P1000 lignin was dissolved in $2 \mathrm{~L}$ of acetone, then $941.2 \mathrm{~g}$ $(6.88 \mathrm{~mol}, 5$ equiv) of potassium carbonate and $113.1 \mathrm{~g}(0.68$ mol, 0.5 equiv) of potassium iodide were dispersed in the lignin solution. Subsequently, the temperature was increased to $60{ }^{\circ} \mathrm{C}$, and $759 \mathrm{~mL}$ (6.88 mol, 5 equiv) of $80 \mathrm{wt} \%$ propargyl bromide solution in toluene was added dropwise into the reaction mixture. The reaction mixture was then refluxed for $24 \mathrm{~h}$. Afterward, the reaction mixture was cooled, and the product was filtered. The solid residue from the reaction mixture was washed with acetone, the filtrates were combined, and the solvent was evaporated. The solid residue was dried at $80{ }^{\circ} \mathrm{C}$ in a vacuum oven overnight. The crude product was dissolved in $500 \mathrm{~mL}$ of ethyl acetate and washed three times with brine. The solvent was evaporated, and the product was dried in a vacuum oven at $80{ }^{\circ} \mathrm{C}$ overnight. $141.5 \mathrm{~g}$ of the propargylated lignin was obtained as a brown powder (yield $64 \%$ ). The propargyl moiety content was determined by measuring the conversion of the phenolic $\mathrm{OH}$, aliphatic $\mathrm{OH}$, and $\mathrm{COOH}$ by ${ }^{31} \mathrm{P}$ NMR spectroscopy. The conversion of phenolic $\mathrm{OH}$, aliphatic $\mathrm{OH}$, and $\mathrm{COOH}$ was 96,64 , and $96 \%$, respectively, which equals to $4.38 \mathrm{mmol} / \mathrm{g}$ of propargyl moieties. The spectra before and after modification are presented in Figure S1.

4.2.2. Preparation of Lignin-Based Resins and Curing via Claisen Rearrangement. Propargylated lignin can be crosslinked via Claisen rearrangement, above $150{ }^{\circ} \mathrm{C} .{ }^{53}$ Here, propargylated $\mathrm{P} 1000$ lignin was cured in bulk, in the presence of the corresponding surfactant to obtain the MC precursor.

$3.75 \mathrm{~g}$ of propargylated P1000 lignin and $11.13 \mathrm{~g}$ of the surfactant (Pluronic P123, Pluronic F127, Kraton G1652, or Solsperse M387) in a 1:3 weight ratio of lignin/surfactant were dissolved in $60 \mathrm{~mL}$ of the green solvent 2-methyltetrahydrofuran to ensure proper mixing of the components. After dissolution, the solvent was evaporated, and the material was transferred to a Binder oven. The Claisen rearrangement reaction (Figure 2) was carried out at $180{ }^{\circ} \mathrm{C}$ for $14 \mathrm{~h}$. The samples were named by the surfactant name. The conversion was determined via FT-IR analysis (Figure S2).

4.2.3. Preparation of MCs. Carbonization of the cured resins was performed in a Carbolite tube furnace type TFZ 12/ $65 / 550$, according to the procedure described by Libbrecht et $a l .{ }^{67} 2.5 \mathrm{~g}$ of resin was weighed into two ceramic pans, and the oven was flushed with nitrogen for $30 \mathrm{~min}$. Then, there were two heating steps: the first to remove the surfactant template and the second to fully carbonize the material. During the first heating step, the sample was heated up to the template decomposition temperature, at a heating rate of $1{ }^{\circ} \mathrm{C} / \mathrm{min}$. When the desired temperature was reached, it was kept isothermal for $2 \mathrm{~h}$. A second heating step with a heating rate of $2{ }^{\circ} \mathrm{C} / \mathrm{min}$ was performed until the desired carbonization temperature was reached $\left(600,800\right.$, or $\left.1000{ }^{\circ} \mathrm{C}\right)$. Then, the temperature was maintained for $3 \mathrm{~h}$ to ensure full carbonization of the sample. After carbonization, the material was cooled to ambient temperature at $5{ }^{\circ} \mathrm{C} / \mathrm{min}$. Flushing, heating, and cooling steps were performed under a constant nitrogen flow of $0.4 \mathrm{NL} / \mathrm{min}$. The obtained material was weighed, grinded, and stored under dry conditions. The different carbons were named by surfactant name_carbonization temperature.

The decomposition temperature of the surfactants was investigated using TGA analysis. Thermal stability of the samples was determined on a TA TGA Q500 instrument in a 
nitrogen atmosphere, from 25 to $700{ }^{\circ} \mathrm{C}$ at a heating rate of 10 ${ }^{\circ} \mathrm{C} / \mathrm{min}$. The thermographs of the surfactants are presented in Figure S3.

4.3. Characterization. 4.3.1. Lignin and Modified Lignin Characterization. The aromatic and aliphatic hydroxyl groups as well as the carboxylic acids (before and after modification) of lignin were determined by ${ }^{31} \mathrm{P}$ NMR spectroscopy after sample derivatization, according to the method described by Korntner et al. ${ }^{93} 10 \mathrm{mg}$ of dried (in a vacuum oven at $80^{\circ} \mathrm{C}$, overnight), lignin-based material was dissolved in a $500 \mu \mathrm{L}$ of anhydrous pyridine and deuterated chloroform mixture (1.6:1, $\mathrm{v} / \mathrm{v})$. Then, $100 \mu \mathrm{L}$ of internal standard solution, cholesterol $(19.7 \mathrm{mg} / \mathrm{mL}$ in anhydrous pyridine and deuterated chloroform mixture, $1.6 / 1, \mathrm{v} / \mathrm{v}, 0.0051 \mathrm{mmol}), 50 \mu \mathrm{L}$ of relaxation agent chromium (III) acetylacetonate $(10 \mathrm{mg} / \mathrm{mL}$, in anhydrous pyridine and deuterated chloroform mixture, 1.6:1, v/v), and $50 \mu \mathrm{L}$ of derivatizing agent, 2-chloro-1,3,2dioxanephospolane, were added to the solution. The solution was stirred for $10 \mathrm{~min}$, transferred into a dry $5 \mathrm{~mm}$ NMR tube, and measured. The measurement was performed on a Bruker AVANCE III HD Nanobay $300 \mathrm{MHz}$ apparatus $(121.49 \mathrm{MHz}$ for ${ }^{31} \mathrm{P}$ NMR experiments) using the standard phosphorus pulse program, at ambient temperature, with 512 scans, relaxation delay ( $5 \mathrm{~s})$, acquisition time $(2 \mathrm{~s})$, transmitter excitation frequency (140 ppm), and spectral width (396 $\mathrm{ppm})$. The chemical shifts were reported in parts per million, and the raw data were processed in MestReNova software. Chemical shifts were referenced from the sharp signal of the reaction product between residual water and 2-chloro-4,4,5,5tetramethyl-1,3,2-dioxaphospholane at $132.2 \mathrm{ppm}$.

Molecular weight of lignin and its dispersity were obtained from GPC analysis. It was performed at $30{ }^{\circ} \mathrm{C}$ using a Waters GPC equipped with a Waters 2414 RI detector. Tetrahydrofuran was used as the eluent at a flow rate of $1 \mathrm{~mL} / \mathrm{min}$. Three linear columns were used (Styragel HR1, Styragel HR4, and Styragel HR5). Lignin samples were dissolved in $1.5 \mathrm{~mL}$ of tetrahydrofuran, and samples were filtered with a PTFE syringe filter (pore size, $0.2 \mu \mathrm{m}$ ) prior to measurements. Molecular weights were obtained relative to polystyrene standards. Lignin was acetylated prior to the measurement, according the procedure described by Gosselink et al. ${ }^{91}$

4.3.2. Resin Characterization. IR spectra of the resins before and after curing were recorded on a PerkinElmer Frontier spectrometer, equipped with Pike technologies GladiATR accessory in the range of $600-4000 \mathrm{~cm}^{-1}$, with a resolution of $2 \mathrm{~cm}^{-1}$ using 32 accumulative scans. The conversion was determined by following the disappearance of the alkyne $\mathrm{C} \equiv \mathrm{C}-\mathrm{H}$ peak at $3320 \mathrm{~cm}^{-1}$, while the peak of the aromatic $\mathrm{C}=\mathrm{C}$ at $1600 \mathrm{~cm}^{-1}$ was used as an internal standard (Figure S2). The conversion was determined based on the integration of the representative peaks with SpectraGryph 1.2 software.

4.3.3. MCs Characterization. Elemental analysis was performed to investigate the chemical composition of the carbon. The measurement was performed with a UNICUBE (Elementar Analysensysteme $\mathrm{GmbH}$ ). For the carbon, hydrogen, nitrogen, and sulfur content, the elemental composition of the synthesized materials was determined by the analysis of the combustion products $\left(\mathrm{CO}_{2}, \mathrm{H}_{2} \mathrm{O}, \mathrm{SO}_{2}\right.$, and $\left.\mathrm{NO}_{2}\right)$. The oxygen content was determined by pyrolysis of the sample in a pyrolysis chamber in a separate experiment. The calibration of the instrument was performed with sulfanilamide as the model compound. Data were analyzed with EAS UNICUBE software.
The nitrogen sorption studies were performed on a Micromeritics Tristar II 3020 surface area and porosimeter analyzer at $77 \mathrm{~K}$. Samples were pretreated at $300{ }^{\circ} \mathrm{C}$ to remove moisture under nitrogen flow for $6 \mathrm{~h}$. The relative pressure range was measured from $2.5 \times 10^{-3}$ to 0.99 . The total pore volume $V_{\text {tot }}$ was calculated as the amount of nitrogen adsorbed at a relative pressure of 0.95 . The pore volumes of micropores $V_{\text {micro }}$ was calculated from the $V-t$ plot. The pore volumes of mesopores and macropores, $V_{\mathrm{BJH}}$, were calculated using $\mathrm{BJH}$ desorption cumulative volume of pores between 17.000 and 3,000.000 ^̊ width. The total surface area $S_{\mathrm{BET}}$ was determined using the BET method. The average pore size $\left(D_{\mathrm{p}} \mathrm{BJH}\right)$ and the PSD were calculated from the desorption branch using the $\mathrm{BJH}$ method. The reported data including $S_{\mathrm{BET}}, V_{\text {tot }}, V_{\text {micro, }}$ $V_{\mathrm{BJH}}$, and PSD were calculated by software MicroActive from Micromeritics.

The morphology of the synthesized materials was investigated using transmission electron microscopy (TEM). The TEM images were acquired on a JOEL JEM 2200-FS TEM with a high tension of $200 \mathrm{kV}$ and $0.1 \mathrm{~s}$ exposure time. For the measurement, the powdered sample was placed on a copper grid (Lacey F/C 200 mesh Cu, Ted Pella Inc.).

XPS measurements were carried out using an Ultra AxisTM spectrometer (Kratos Analytical). The samples were irradiated with monoenergetic Al K1,2 radiation $(1486.6 \mathrm{eV})$, and the spectra were taken at a power of $144 \mathrm{~W}(12 \mathrm{kV} \times 12 \mathrm{~mA})$. The aliphatic carbon $(\mathrm{C}-\mathrm{C}$ and $\mathrm{C}-\mathrm{H})$ at a binding energy of 285 $\mathrm{eV}$ (C 1s photoline) was used to determine the charging. The spectral resolution - the full width at half-maximum of the ester carbon from poly(ethylene terephthalate) (PET)-was better than $0.68 \mathrm{eV}$ for the elemental spectra. The elemental concentration is given in weight $\%$, but it should be considered that this method can detect all elements except hydrogen and helium. The information depth is about $10 \mathrm{~nm}$.

4.4. HA Adsorption. The HA adsorption capacity of the synthesized carbons was determined using the methodology described by Libbrecht et al. ${ }^{67}$ First, a $500 \mathrm{mg} / \mathrm{L}$ HA solution was prepared by dispersing $500 \mathrm{mg}$ of $\mathrm{HA}$ in $1 \mathrm{~L}$ of deionized water. HA was dissolved by adding $0.1 \mathrm{M}$ sodium hydroxide solution until it reached $\mathrm{pH} \mathrm{12,} \mathrm{and} \mathrm{ultrasonic} \mathrm{treatment} \mathrm{was}$ carried out for $30 \mathrm{~min}$. After dissolution, the solution was neutralized to $\mathrm{pH} 7$ with $0.1 \mathrm{M}$ hydrochloric acid solution. Next, $10 \mathrm{mg}$ of the adsorbent was added to $50 \mathrm{~mL}$ of the 500 $\mathrm{mg} / \mathrm{L} \mathrm{HA}$ solution. These mixtures were incubated in a thermostatic shaker (Infors HT Multitron Standard) at $25^{\circ} \mathrm{C}$ and $200 \mathrm{rpm}$ for 7 days to ensure equilibrium. After incubation, the solution was filtered through a $0.45 \mu \mathrm{m}$ PET syringe filter, and its HA concentration was measured by UVvis at $254 \mathrm{~nm}$ using a Thermo Scientific Evolution $60 \mathrm{UV}-$ vis spectrometer with VISIONlight 4 software. The HA concentration of the $500 \mathrm{mg} / \mathrm{L}$ solution was determined by the same procedure (filtration and UV-vis analysis). All adsorption experiments were performed in triplicate. The adsorption capacity was calculated using the equation

$$
q_{\mathrm{e}}=\frac{\left(C_{0}-C_{\mathrm{e}}\right) V}{m}
$$

where $q_{\mathrm{e}}(\mathrm{mg} / \mathrm{g})$ is the HA adsorption capacity at equilibrium, $C_{0}$ and $C_{\mathrm{e}}(\mathrm{mg} / \mathrm{L})$ are the initial and equilibrium concentration of HA, $m(\mathrm{mg})$ is the mass of the adsorbent, and $V(\mathrm{~L})$ is the solution volume. 


\section{ASSOCIATED CONTENT}

\section{(5) Supporting Information}

The Supporting Information is available free of charge at https://pubs.acs.org/doi/10.1021/acsomega.1c01475.

${ }^{31} \mathrm{P}$ NMR spectra before and after propargylation of P1000 lignin, TGA thermographs of the used surfactants, IR spectra before and after Claisen rearrangement, nitrogen sorption isotherm, and PSD of the resins carbonized at 600 and $1000{ }^{\circ} \mathrm{C}(\mathrm{PDF})$

\section{AUTHOR INFORMATION}

\section{Corresponding Authors}

Jeriffa De Clercq - Faculty of Engineering and Architecture, Department of Materials, Textiles and Chemical Engineering, Industrial Catalysis and Adsorption Technology (INCAT), Ghent University, 9000 Ghent, Belgium; O orcid.org/00000003-2858-1276; Email: katrien.bernaerts@ maastrichtuniversity.nl

Katrien V. Bernaerts - Faculty of Science and Engineering, Aachen-Maastricht Institute for Biobased Materials (AMIBM), Maastricht University, Geleen 6167 RD, The Netherland; 이이이.org/0000-0002-2939-2963; Email: jeriffa.declercq@ugent.be

\section{Authors}

Monika A. Jedrzejczyk - Faculty of Science and Engineering, Aachen-Maastricht Institute for Biobased Materials (AMIBM), Maastricht University, Geleen 6167 RD, The Netherland

Julian Engelhardt - Faculty of Science and Engineering, Aachen-Maastricht Institute for Biobased Materials (AMIBM), Maastricht University, Geleen 6167 RD, The Netherland

Marko R. Djokic - Faculty of Engineering and Architecture, Department of Materials, Textiles and Chemical Engineering, Laboratorium for Chemical Technology (LCT), Ghent University, 9052 Ghent, Belgium

Vitaliy Bliznuk - Faculty of Engineering and Architecture, Department of Electrical Energy, Metals, Mechanical Constructions and Systems, Ghent University, 9052 Ghent, Belgium

Kevin M. Van Geem - Faculty of Engineering and Architecture, Department of Materials, Textiles and Chemical Engineering, Laboratorium for Chemical Technology (LCT), Ghent University, 9052 Ghent, Belgium; 이이.org/00000003-4191-4960

An Verberckmoes - Faculty of Engineering and Architecture, Department of Materials, Textiles and Chemical Engineering, Industrial Catalysis and Adsorption Technology (INCAT),

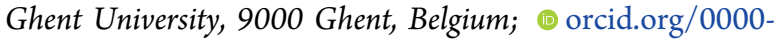
0003-2309-4874

Complete contact information is available at:

https://pubs.acs.org/10.1021/acsomega.1c01475

\section{Author Contributions}

The manuscript was written through contributions of all authors. All authors have given approval to the final version of the manuscript.

\section{Funding}

This work was funded by Chemelot InSciTe (project Lignin Riches), by the European Interreg V Flanders-the Netherlands program BIO-HArT and by the Ministry of Economic Affairs and Climate from the Netherlands. This work was done as a part of the Erasmus Plus program, between Maastricht University and Ghent University by Julian Engelhardt (January-May 2019).

\section{Notes}

The authors declare no competing financial interest.

\section{ACKNOWLEDGMENTS}

Arno de Reviere from the INCAT group at the Ghent University is acknowledged for the help with the nitrogen sorption, and Nadia De Paepe from the INCAT group at the Ghent University is acknowledged for the help with the carbonization and HA adsorption tests. We would like to thank Panos Kouris from the Inorganic Materials and Catalysis group at the Eindhoven University of Technology for delivering P1000 lignin sample used in this research. Joachim Roes, Robert Kaufmann, and Andrij Pich from the DWI LeibnizInstitute for Interactive Materials at RWTH Aachen are acknowledged for the help with XPS experiments.

\section{ABBREVIATIONS}

$\begin{array}{ll}\text { BET } & \text { Brunauer-Emmett-Teller } \\ \text { BJH } & \text { Barrett-Joyner-Halenda } \\ \text { EISA } & \text { evaporation-induced self-assembly } \\ \text { GPC } & \text { gel permeation chromatography } \\ \text { HA } & \text { humic acid } \\ \text { MCs } & \text { mesoporous carbons } \\ \text { NMR } & \text { nuclear magnetic resonance } \\ \text { PEO } & \text { poly(ethylene oxide) } \\ \text { PET } & \text { poly(ethylene terephthalate) } \\ \text { PO } & \text { poly(propylene oxide) } \\ \text { PSD } & \text { pore size distribution } \\ \text { PTFE } & \text { polytetrafluoroethylene } \\ \text { SEBS } & \text { styrene-ethylene-butylene-styrene } \\ \text { TEM } & \text { transmission electron microscopy } \\ \text { TGA } & \text { thermogravimetric analysis } \\ \text { XPS } & \text { X-ray photoelectron spectroscopy }\end{array}$

\section{REFERENCES}

(1) Finley, J. W.; Seiber, J. N. The Nexus of Food, Energy, and Water. J. Agric. Food Chem. 2014, 62, 6255-6262.

(2) Azadi, P.; Inderwildi, O. R.; Farnood, R.; King, D. A. Liquid fuels, hydrogen and chemicals from lignin: A critical review. Renew. Sustain. Energy Rev. 2013, 21, 506-523.

(3) Caes, B. R.; Teixeira, R. E.; Knapp, K. G.; Raines, R. T. Biomass to Furanics: Renewable Routes to Chemicals and Fuels. ACS Sustainable Chem. Eng. 2015, 3, 2591-2605.

(4) Delidovich, I.; Hausoul, P. J. C.; Deng, L.; Pfützenreuter, R.; Rose, M.; Palkovits, R. Alternative Monomers Based on Lignocellulose and Their Use for Polymer Production. Chem. Rev. 2016, 116, $1540-1599$.

(5) Mika, L. T.; Cséfalvay, E.; Németh, Á. Catalytic Conversion of Carbohydrates to Initial Platform Chemicals: Chemistry and Sustainability. Chem. Rev. 2018, 118, 505-613.

(6) Schutyser, W.; Renders, T.; Van den Bosch, S.; Koelewijn, S.-F.; Beckham, G. T.; Sels, B. F. Chemicals from lignin: an interplay of lignocellulose fractionation, depolymerisation, and upgrading. Chem. Soc. Rev. 2018, 47, 852-908.

(7) Sun, Z.; Barta, K. Cleave and couple: toward fully sustainable catalytic conversion of lignocellulose to value added building blocks and fuels. Chem. Commun. 2018, 54, 7725-7745.

(8) Sun, Z.; Fridrich, B.; de Santi, A.; Elangovan, S.; Barta, K. Bright Side of Lignin Depolymerization: Toward New Platform Chemicals. Chem. Rev. 2018, 118, 614-678. 
(9) Vanholme, R.; Demedts, B.; Morreel, K.; Ralph, J.; Boerjan, W. Lignin Biosynthesis and Structure. Plant Physiol. 2010, 153, 895-905. (10) Figueiredo, P.; Lintinen, K.; Hirvonen, J. T.; Kostiainen, M. A.; Santos, H. A. Properties and chemical modifications of lignin: Towards lignin-based nanomaterials for biomedical applications. Prog. Mater. Sci. 2018, 93, 233-269.

(11) Kai, D.; Tan, M. J.; Chee, P. L.; Chua, Y. K.; Yap, Y. L.; Loh, X. $\mathrm{J}$. Towards lignin-based functional materials in a sustainable world. Green Chem. 2016, 18, 1175-1200.

(12) Bajwa, D. S.; Pourhashem, G.; Ullah, A. H.; Bajwa, S. G. A concise review of current lignin production, applications, products and their environmental impact. Ind. Crops Prod. 2019, 139, 111526111537.

(13) Balakshin, M. Y.; Capanema, E. A.; Sulaeva, I.; Schlee, P.; Huang, Z.; Feng, M.; Borghei, M.; Rojas, O. J.; Potthast, A.; Rosenau, T. New Opportunities in the Valorization of Technical Lignins. ChemSusChem 2021, 14, 1016-1036.

(14) Yu, O.; Kim, K. H. Lignin to Materials: A Focused Review on Recent Novel Lignin Applications. Appl. Sci. 2020, 10, 4626-4642.

(15) Chatterjee, S.; Saito, T. Lignin-Derived Advanced Carbon Materials. ChemSusChem 2015, 8, 3941-3958.

(16) Inagaki, M.; Toyoda, M.; Soneda, Y.; Tsujimura, S.; Morishita, T. Templated mesoporous carbons: Synthesis and applications. Carbon 2016, 107, 448-473.

(17) Lim, E.; Jo, C.; Lee, J. A mini review of designed mesoporous materials for energy-storage applications: from electric double-layer capacitors to hybrid supercapacitors. Nanoscale 2016, 8, 7827-7833.

(18) Suib, S. L. A Review of Recent Developments of Mesoporous Materials. Chem. Rec. 2017, 17, 1169-1183.

(19) Xin, W.; Song, Y. Mesoporous carbons: recent advances in synthesis and typical applications. RSC Adv. 2015, 5, 83239-83285.

(20) Benzigar, M. R.; Talapaneni, S. N.; Joseph, S.; Ramadass, K.; Singh, G.; Scaranto, J.; Ravon, U.; Al-Bahily, K.; Vinu, A. Recent advances in functionalized micro and mesoporous carbon materials: synthesis and applications. Chem. Soc. Rev. 2018, 47, 2680-2721.

(21) Gang, D.; Uddin Ahmad, Z.; Lian, Q.; Yao, L.; Zappi, M. E. A review of adsorptive remediation of environmental pollutants from aqueous phase by ordered mesoporous carbon. Chem. Eng. J. 2021, 403, 126286-126304.

(22) Ferrero, G. A.; Sevilla, M.; Fuertes, A. B. Mesoporous carbons synthesized by direct carbonization of citrate salts for use as highperformance capacitors. Carbon 2015, 88, 239-251.

(23) Xie, Y.; Kocaefe, D.; Chen, C.; Kocaefe, Y. Review of Research on Template Methods in Preparation of Nanomaterials. J. Nanomater. 2016, 2016, 1-10.

(24) Lyu, L.; Seong, K.-d.; Ko, D.; Choi, J.; Lee, C.; Hwang, T.; Cho, Y.; Jin, X.; Zhang, W.; Pang, H.; Piao, Y. Recent development of biomass-derived carbons and composites as electrode materials for supercapacitors. Mater. Chem. Front. 2019, 3, 2543-2570.

(25) Chuenchom, L.; Kraehnert, R.; Smarsly, B. M. Recent progress in soft-templating of porous carbon materials. Soft Matter 2012, 8, 10801-10812.

(26) Enterría, M.; Figueiredo, J. L. Nanostructured mesoporous carbons: Tuning texture and surface chemistry. Carbon 2016, 108, 79-102.

(27) Libbrecht, W.; Verberckmoes, A.; Thybaut, J. W.; Van Der Voort, P.; De Clercq, J. Soft templated mesoporous carbons: Tuning the porosity for the adsorption of large organic pollutants. Carbon 2017, 116, 528-546.

(28) Saha, D.; Warren, K. E.; Naskar, A. K. Soft-templated mesoporous carbons as potential materials for oral drug delivery. Carbon 2014, 71, 47-57.

(29) Chandran, M.; Shamna, I.; Anusha, A.; Bhagiyalakshmi, M. Synthesis of mesoporous carbon-polymeric hybrid material for energy storage application. SN Appl. Sci. 2019, 1, 1-10.

(30) Libbrecht, W.; Deruyck, F.; Poelman, H.; Verberckmoes, A.; Thybaut, J.; De Clercq, J.; Van Der Voort, P. Optimization of soft templated mesoporous carbon synthesis using Definitive Screening Design. Chem. Eng. J. 2015, 259, 126-134.
(31) Malgras, V.; Tang, J.; Wang, J.; Kim, J.; Torad, N. L.; Dutta, S.; Ariga, K.; Hossain, M. S. A.; Yamauchi, Y.; Wu, K. C. W. Fabrication of Nanoporous Carbon Materials with Hard- and Soft-Templating Approaches: A Review. J. Nanosci. Nanotechnol. 2019, 19, 3673-3685.

(32) Tsouris, C.; Mayes, R.; Kiggans, J.; Sharma, K.; Yiacoumi, S.; DePaoli, D.; Dai, S. Mesoporous carbon for capacitive deionization of saline water. Environ. Sci. Technol. 2011, 45, 10243-10249.

(33) González-García, P. Activated carbon from lignocellulosics precursors: A review of the synthesis methods, characterization techniques and applications. Renew. Sustain. Energy Rev. 2018, 82, 1393-1414.

(34) Liu, Y.; Chen, J.; Cui, B.; Yin, P.; Zhang, C. Design and Preparation of Biomass-Derived Carbon Materials for Supercapacitors: A Review. C 2018, 4, 53-85.

(35) Varma, R. S. Biomass-Derived Renewable Carbonaceous Materials for Sustainable Chemical and Environmental Applications. ACS Sustainable Chem. Eng. 2019, 7, 6458-6470.

(36) Xie, L.; Jin, Z.; Dai, Z.; Chang, Y.; Jiang, X.; Wang, H. Porous carbons synthesized by templating approach from fluid precursors and their applications in environment and energy storage: A review. Carbon 2020, 170, 100-118.

(37) Danish, M.; Ahmad, T. A review on utilization of wood biomass as a sustainable precursor for activated carbon production and application. Renew. Sustain. Energy Rev. 2018, 87, 1-21.

(38) Puziy, A. M.; Poddubnaya, O. I.; Sevastyanova, O. Carbon Materials from Technical Lignins: Recent Advances. Top. Curr. Chem. 2018, 376, 133.

(39) Suhas; Carrott, P. J. M.; Ribeiro Carrott, M. M. L. Ligninfrom natural adsorbent to activated carbon: A review. Bioresour. Technol. 2007, 98, 2301-2312.

(40) Chen, F.; Zhou, W.; Yao, H.; Fan, P.; Yang, J.; Fei, Z.; Zhong, $\mathrm{M}$. Self-assembly of $\mathrm{NiO}$ nanoparticles in lignin-derived mesoporous carbons for supercapacitor applications. Green Chem. 2013, 15, 30573063.

(41) Herou, S.; Ribadeneyra, M. C.; Madhu, R.; Araullo-Peters, V.; Jensen, A.; Schlee, P.; Titirici, M. Ordered mesoporous carbons from lignin: a new class of biobased electrodes for supercapacitors. Green Chem. 2019, 21, 550-559.

(42) Qin, H.; Jian, R.; Bai, J.; Tang, J.; Zhou, Y.; Zhu, B.; Zhao, D.; Ni, Z.; Wang, L.; Liu, W.; Zhou, Q.; Li, X. Influence of Molecular Weight on Structure and Catalytic Characteristics of Ordered Mesoporous Carbon Derived from Lignin. ACS Omega 2018, 3, $1350-1356$

(43) Saha, D.; Payzant, E. A.; Kumbhar, A. S.; Naskar, A. K. Sustainable mesoporous carbons as storage and controlled-delivery media for functional molecules. ACS Appl. Mater. Interfaces 2013, 5, $5868-5874$

(44) Gan, L.; Lyu, L.; Shen, T.; Wang, S. Sulfonated lignin-derived ordered mesoporous carbon with highly selective and recyclable catalysis for the conversion of fructose into 5-hydroxymethylfurfural. Appl. Catal., A 2019, 574, 132-143.

(45) Wang, S.; Sima, G.; Cui, Y.; Chang, L.; Gan, L. Preparations of lignin-derived ordered mesoporous carbon by self-assembly in organic solvent and aqueous solution: Comparison in textural property. Mater. Lett. 2020, 264, 127318-127321.

(46) Guo, N.; Li, M.; Sun, X.; Wang, F.; Yang, R. Enzymatic hydrolysis lignin derived hierarchical porous carbon for supercapacitors in ionic liquids with high power and energy densities. Green Chem. 2017, 19, 2595-2602.

(47) Hung, Y.-H.; Liu, T.-Y.; Chen, H.-Y. Renewable Coffee WasteDerived Porous Carbons as Anode Materials for High-Performance Sustainable Microbial Fuel Cells. ACS Sustainable Chem. Eng. 2019, 7, 16991-16999.

(48) Zhang, L.; You, T.; Zhou, T.; Zhou, X.; Xu, F. Interconnected Hierarchical Porous Carbon from Lignin-Derived Byproducts of Bioethanol Production for Ultra-High Performance Supercapacitors. ACS Appl. Mater. Interfaces 2016, 8, 13918-13925.

(49) Zhang, W.; Cheng, H.; Niu, Q.; Fu, M.; Huang, H.; Ye, D. Microbial Targeted Degradation Pretreatment: A Novel Approach to 
Preparation of Activated Carbon with Specific Hierarchical Porous Structures, High Surface Areas, and Satisfactory Toluene Adsorption Performance. Environ. Sci. Technol. 2019, 53, 7632-7640.

(50) Supanchaiyamat, N.; Jetsrisuparb, K.; Knijnenburg, J. T. N.; Tsang, D. C. W.; Hunt, A. J. Lignin materials for adsorption: Current trend, perspectives and opportunities. Bioresour. Technol. 2019, 272, $570-581$.

(51) Saha, D.; Van Bramer, S. E.; Orkoulas, G.; Ho, H.-C.; Chen, J.; Henley, D. K. CO2 capture in lignin-derived and nitrogen-doped hierarchical porous carbons. Carbon 2017, 121, 257-266.

(52) Li, Z.; Xiao, D.; Ge, Y.; Koehler, S. Surface-Functionalized Porous Lignin for Fast and Efficient Lead Removal from Aqueous Solution. ACS Appl. Mater. Interfaces 2015, 7, 15000-15009.

(53) Sen, S.; Sadeghifar, H.; Argyropoulos, D. S. Kraft Lignin Chain Extension Chemistry via Propargylation, Oxidative Coupling, and Claisen Rearrangement. Biomacromolecules 2013, 14, 3399-3408.

(54) Wang, M.; Yang, L. Lignin Functionalized by Thermally Curable Propargyl Groups as Heat-Resistant Polymeric Material. J. Polym. Environ. 2012, 20, 783-787.

(55) Sadeghifar, H.; Sen, S.; Patil, S. V.; Argyropoulos, D. S. Toward Carbon Fibers from Single Component Kraft Lignin Systems: Optimization of Chain Extension Chemistry. ACS Sustainable Chem. Eng. 2016, 4, 5230-5237.

(56) Solsperse Hyperdispersants Product Guide. https://www. lubrizol.com/Coatings/Brands/Solsperse-Hyperdispersants (accessed 29.01.2021)

(57) Bhatnagar, A.; Sillanpää, M. Removal of natural organic matter (NOM) and its constituents from water by adsorption - A review. Chemosphere 2017, 166, 497-510.

(58) Matilainen, A.; Gjessing, E. T.; Lahtinen, T.; Hed, L.; Bhatnagar, A.; Sillanpää, M. An overview of the methods used in the characterisation of natural organic matter (NOM) in relation to drinking water treatment. Chemosphere 2011, 83, 1431-1442.

(59) Li, A.; Zhao, X.; Liu, H.; Qu, J. Characteristic transformation of humic acid during photoelectrocatalysis process and its subsequent disinfection byproduct formation potential. Water Res. 2011, 45, 6131-6140.

(60) Tang, W.-W.; Zeng, G.-M.; Gong, J.-L.; Liang, J.; Xu, P.; Zhang, C.; Huang, B.-B. Impact of humic/fulvic acid on the removal of heavy metals from aqueous solutions using nanomaterials: A review. Sci. Total Environ. 2014, 468-469, 1014-1027.

(61) Sillanpää, M.; Ncibi, M. C.; Matilainen, A.; Vepsäläinen, M. Removal of natural organic matter in drinking water treatment by coagulation: A comprehensive review. Chemosphere 2018, 190, 5471.

(62) Islam, M. A.; Morton, D. W.; Johnson, B. B.; Angove, M. J. Adsorption of humic and fulvic acids onto a range of adsorbents in aqueous systems, and their effect on the adsorption of other species: A review. Sep. Purif. Technol. 2020, 247, 116949-116968.

(63) Reshadi, M. A. M.; Bazargan, A.; McKay, G. A review of the application of adsorbents for landfill leachate treatment: Focus on magnetic adsorption. Sci. Total Environ. 2020, 731, 138863-138878.

(64) Srinivasadesikan, V.; Dai, J.-K.; Lee, S.-L. Quantum mechanistic insights on aryl propargyl ether Claisen rearrangement. Org. Biomol. Chem. 2014, 12, 4163-4171.

(65) Kawamoto, H. Lignin pyrolysis reactions. J. Wood Sci. 2017, 63, 117-132.

(66) Yu, H.; Zhang, Z.; Li, Z.; Chen, D. Characteristics of tar formation during cellulose, hemicellulose and lignin gasification. Fuel 2014, 118, 250-256.

(67) Libbrecht, W.; Verberckmoes, A.; Thybaut, J. W.; Van Der Voort, P.; De Clercq, J. Tunable Large Pore Mesoporous Carbons for the Enhanced Adsorption of Humic Acid. Langmuir 2017, 33, 67696777.

(68) Thommes, M.; Kaneko, K.; Neimark, A. V.; Olivier, J. P.; Rodriguez-Reinoso, F.; Rouquerol, J.; Sing, K. S. W. Physisorption of gases, with special reference to the evaluation of surface area and pore size distribution (IUPAC Technical Report). Pure Appl. Chem. 2015, $87,1051-1069$
(69) Muylaert, I.; Borgers, M.; Bruneel, E.; Schaubroeck, J.; Verpoort, F.; Van Der Voort, P. Ultra stable ordered mesoporous phenol/formaldehyde polymers as a heterogeneous support for vanadium oxide. Chem. Commun. 2008, 37, 4475-4477.

(70) McKeown, N. B.; Budd, P. M.; Msayib, K. J.; Ghanem, B. S.; Kingston, H. J.; Tattershall, C. E.; Makhseed, S.; Reynolds, K. J.; Fritsch, D. Polymers of Intrinsic Microporosity (PIMs): Bridging the Void between Microporous and Polymeric Materials. Chem.-Eur J. 2005, 11, 2610-2620.

(71) Muylaert, I.; Verberckmoes, A.; De Decker, J.; Van Der Voort, P. Ordered mesoporous phenolic resins: Highly versatile and ultra stable support materials. Adv. Colloid Interface Sci. 2012, 175, 39-51.

(72) Azadfar, M.; Hiscox, W. C.; Chen, S. Solubilization of lignin in copolymer micelles in aqueous solution. Colloids Surf., A 2016, 503, $1-10$.

(73) Jiao, J.; Cai, Y.; Liu, P.; Liu, P. Influence of template on the structure of mesoporous carbon prepared with novalac resin as carbon precursor. J. Porous Mater. 2013, 20, 1247-1255.

(74) Li, Q.; Jiang, R.; Dou, Y.; Wu, Z.; Huang, T.; Feng, D.; Yang, J.; Yu, A.; Zhao, D. Synthesis of mesoporous carbon spheres with a hierarchical pore structure for the electrochemical double-layer capacitor. Carbon 2011, 49, 1248-1257.

(75) Saha, D.; Li, Y.; Bi, Z.; Chen, J.; Keum, J. K.; Hensley, D. K.; Grappe, H. A.; Meyer, H. M., 3rd; Dai, S.; Paranthaman, M. P.; Naskar, A. K. Studies on supercapacitor electrode material from activated lignin-derived mesoporous carbon. Langmuir 2014, 30, 900-910.

(76) Chen, J. P.; Wu, S. Simultaneous adsorption of copper ions and humic acid onto an activated carbon. J. Colloid Interface Sci. 2004, 280, 334-342.

(77) Eustáquio, H. M. B.; Lopes, C. W.; da Rocha, R. D.; Cardoso, B. D.; Pergher, S. B. C. Modification of Activated Carbon for the Adsorption of Humic Acid. Adsorpt. Sci. Technol. 2015, 33, 117-126.

(78) Maghsoodloo, S.; Noroozi, B.; Haghi, A. K.; Sorial, G. A. Consequence of chitosan treating on the adsorption of humic acid by granular activated carbon. J. Hazard. Mater. 2011, 191, 380-387.

(79) Tavengwa, N. T.; Chimuka, L.; Tichagwa, L. Equilibrium and kinetic studies on the adsorption of humic acid onto cellulose and powdered activated carbon. Desalin. Water Treat. 2015, 57, 1684316854.

(80) Yang, K.; Fox, J. T. Adsorption of Humic Acid by AcidModified Granular Activated Carbon and Powder Activated Carbon. J. Environ. Eng. 2018, 144, 4018104-4018114.

(81) Liu, F.; Xu, Z.; Wan, H.; Wan, Y.; Zheng, S.; Zhu, D. Enhanced adsorption of humic acids on ordered mesoporous carbon compared with microporous activated carbon. Environ. Toxicol. Chem. 2011, 30, 793-800.

(82) Lorenc-Grabowska, E.; Gryglewicz, G. Adsorption of lignitederived humic acids on coal-based mesoporous activated carbons. J. Colloid Interface Sci. 2005, 284, 416-423.

(83) Stárek, J.; Zukal, A.; Rathouský, J. Comparison of the adsorption of humic acids from aqueous solutions on active carbon and activated charcoal cloths. Carbon 1994, 32, 207-211.

(84) Kołodziej, A.; Fuentes, M.; Baigorri, R.; Lorenc-Grabowska, E.; García-Mina, J. M.; Burg, P.; Gryglewicz, G. Mechanism of adsorption of different humic acid fractions on mesoporous activated carbons with basic surface characteristics. Adsorption 2014, 20, 667-675.

(85) Wu, F.-C.; Tseng, R.-L.; Juang, R.-S. Adsorption of dyes and humic acid from water using chitosan-encapsulated activated carbon. J. Chem. Technol. Biotechnol. 2002, 77, 1269-1279.

(86) Yu, H.; Zhang, Q.; Dahl, M.; Joo, J. B.; Wang, X.; Wang, L.; Yin, Y. Dual-Pore Carbon Shells for Efficient Removal of Humic Acid from Water. Chemistry 2017, 23, 16249-16256.

(87) Anzai, T.; Matsuura, Y.; Sugawara, T.; Miura, O. Removal of Humic Acid in Water by Rice Hull Magnetic Activated Carbon and Magnetic Separation. IEEE Trans. Appl. Supercond. 2016, 26, 1-4.

(88) Wen, T.; Wang, J.; Yu, S.; Chen, Z.; Hayat, T.; Wang, X. Magnetic Porous Carbonaceous Material Produced from Tea Waste 
for Efficient Removal of As(V), Cr(VI), Humic Acid, and Dyes. ACS Sustainable Chem. Eng. 2017, 5, 4371-4380.

(89) Espinoza-Acosta, J. L.; Torres-Chávez, P. I.; Olmedo-Martínez, J. L.; Vega-Rios, A.; Flores-Gallardo, S.; Zaragoza-Contreras, E. A. Lignin in storage and renewable energy applications: A review. J. Energy Chem. 2018, 27, 1422-1438.

(90) Zhu, J.; Yan, C.; Zhang, X.; Yang, C.; Jiang, M.; Zhang, X. A sustainable platform of lignin: From bioresources to materials and their applications in rechargeable batteries and supercapacitors. Prog. Energy Combust. Sci. 2020, 76, 100788-100812.

(91) Gosselink, R. J. A.; Abächerli, A.; Semke, H.; Malherbe, R.; Käuper, P.; Nadif, A.; van Dam, J. E. G. Analytical protocols for characterisation of sulphur-free lignin. Ind. Crops Prod. 2004, 19, 271-281.

(92) Constant, S.; Wienk, H. L. J.; Frissen, A. E.; Peinder, P. d.; Boelens, R.; van Es, D. S.; Grisel, R. J. H.; Weckhuysen, B. M.; Huijgen, W. J. J.; Gosselink, R. J. A.; Bruijnincx, P. C. A. New insights into the structure and composition of technical lignins: a comparative characterisation study. Green Chem. 2016, 18, 2651-2665.

(93) Korntner, P.; Sumerskii, I.; Bacher, M.; Rosenau, T.; Potthast, A. Characterization of technical lignins by NMR spectroscopy: optimization of functional group analysis by 31P NMR spectroscopy. Holzforschung 2015, 69, 807-814. 